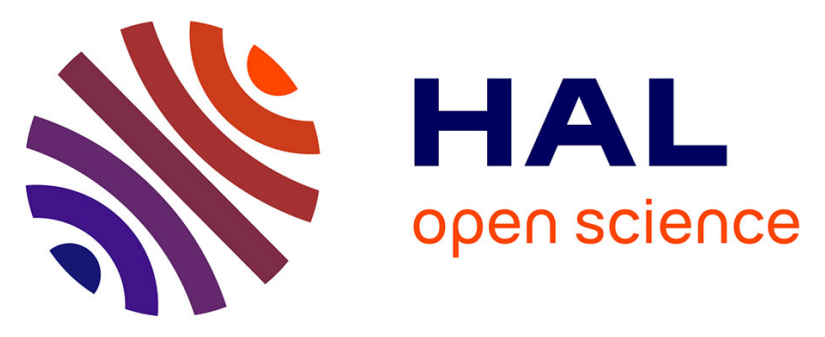

\title{
alpha,omega-Bis(trialkoxysilyl) difunctionalized polycyclooctenes from ruthenium-catalyzed chain-transfer ring-opening metathesis polymerization
}

Xiaolu Michel, Stéphane Fouquay, Guillaume Michaud, Frédéric Simon, Jean-Michel Brusson, Jean-François Carpentier, Sophie M. Guillaume

\section{To cite this version:}

Xiaolu Michel, Stéphane Fouquay, Guillaume Michaud, Frédéric Simon, Jean-Michel Brusson, et al.. alpha,omega-Bis(trialkoxysilyl) difunctionalized polycyclooctenes from ruthenium-catalyzed chaintransfer ring-opening metathesis polymerization. Polymer Chemistry, 2016, 7 (29), pp.4810-4823. 10.1039/c6py00849f . hal-01357417

HAL Id: hal-01357417

https://hal-univ-rennes1.archives-ouvertes.fr/hal-01357417

Submitted on 2 Dec 2016

HAL is a multi-disciplinary open access archive for the deposit and dissemination of scientific research documents, whether they are published or not. The documents may come from teaching and research institutions in France or abroad, or from public or private research centers.
L'archive ouverte pluridisciplinaire HAL, est destinée au dépôt et à la diffusion de documents scientifiques de niveau recherche, publiés ou non, émanant des établissements d'enseignement et de recherche français ou étrangers, des laboratoires publics ou privés. 
,$\omega$-Bis(Trialkoxysilyl) Difunctionalized Polycyclooctenes from Ruthenium-Catalyzed ChainTransfer Ring-Opening Metathesis Polymerization

Xiaolu Michel, ${ }^{\mathrm{a}}$ Stéphane Fouquay, ${ }^{\mathrm{b}}$ Guillaume Michaud, ${ }^{\mathrm{c}}$ Frédéric Simon, ${ }^{\mathrm{c}}$ Jean-Michel Brusson, ${ }^{\mathrm{d}}$ Jean-François Carpentier, ${ }^{\mathrm{a}, *}$ and Sophie M. Guillaume ${ }^{\mathrm{a}, *}$

${ }^{a}$ Institut des Sciences Chimiques de Rennes (ISCR), UMR 6226 CNRS - Université de Rennes 1, Campus de Beaulieu, 263 Avenue du Général Leclerc, F-35042 Rennes Cedex, France ${ }^{b}$ BOSTIK S.A., 253, Avenue du Président Wilson, F-93211 La Plaine Saint-Denis, France ${ }^{c}$ BOSTIK, ZAC du Bois de Plaisance, 101, Rue du Champ Cailloux, F-60280 Venette, France

${ }^{d}$ Total S.A., Corporate Science, Tour Michelet A, 24 Cours Michelet - La Défense 10, F-92069 Paris La Défense Cedex, France

\footnotetext{
*Corresponding authors: jean-francois.carpentier@univ-rennes1.fr; sophie.guillaume@univ$\underline{\text { rennes1.fr }}$
} 


\begin{abstract}
.
The ring-opening metathesis polymerization/cross-metathesis (ROMP/CM) of cyclooctene (COE) using bis(trialkoxysilyl)alkenes as chain-transfer agents (CTAs) and $\mathrm{Ru}$ catalysts to afford difunctionalized polyolefins is reported. Formation of telechelic $\alpha, \omega$-bis(trialkoxysilyl) polycycloolefins (DF) with controlled molar mass values takes place quite selectively ( $>90 \mathrm{wt} \%)$, along with minor amounts of cyclic non-functionalized polymers (CNF), as evidenced by NMR, MALDI-ToF MS, SEC analyses and fractionation experiments. The nature of the CTA and catalyst influenced much the efficiency and selectivity of the reaction. $(\mathrm{MeO})_{3} \mathrm{SiCH}_{2} \mathrm{CH}=\mathrm{CHCH}_{2} \mathrm{Si}(\mathrm{OMe})_{3}$ (2) and $(\mathrm{MeO})_{3} \mathrm{Si}\left(\mathrm{CH}_{2}\right)_{3} \mathrm{NHC}(\mathrm{O}) \mathrm{OCH}_{2} \mathrm{CH}=\mathrm{CHCH}_{2} \mathrm{OC}(\mathrm{O}) \mathrm{NH}\left(\mathrm{CH}_{2}\right)_{3} \mathrm{Si}(\mathrm{OMe})_{3}$ (5) proved the most efficient CTAs in terms of reactivity, catalyst productivity and selectivity towards DF. Diurethane CTA 5 is easily prepared, and can also be conveniently generated in situ during the ROMP/CM. Grubbs' $2^{\text {nd }}$-generation catalyst $(\mathbf{G} 2)$ and Hoveyda-Grubbs's catalyst (HG2) afforded the best compromise in terms of selectivity and productivity, with turnover numbers up to 95000 $\operatorname{mol}(\mathrm{COE}) \cdot \mathrm{mol}(\mathrm{Ru})^{-1}$ and $5000 \operatorname{mol}(\mathrm{CTA}) \cdot \mathrm{mol}(\mathrm{Ru})^{-1}$.
\end{abstract}

Keywords: alkoxysilyl, chain-transfer agent, polycyclooctene, ring-opening metathesis polymerization (ROMP), ruthenium catalyst, telechelic polymer 


\section{Introduction}

Alkoxysilyl-functionalized polymers are widely used in sealing and adhesive applications. Upon polycondensation of alkoxysilyl groups under the action of moisture, the resulting siloxane network structure ensures a successful and resistant assembly. ${ }^{1,2}$ Several methods are known to prepare alkoxysilyl-functionalized polyolefins. One relies on living anionic polymerization of alkoxysilyl-vinyl or -diene monomers, to generate polymers with alkoxysilyl pendant functions. . $^{3,5,6,7,8,9,10}$ Post-polymerization reactions of alkali metalterminated polymers using chlorotrialkoxysilane or tetraalkoxysilane offer an efficient approach toward alkoxysilyl end-functionalized polymers. ${ }^{11,12,13,14}$ Alkoxysilylfunctionalized polymers can also be generated by free-radical polymerization of alkoxysilyldiene monomers. ${ }^{11,13,15,16,17,18}$ Hydrosilylation provides another efficient entry towards alkoxysilyl functionalized polymers; for instance, the highly selective hydrosilylation of 1,2polybutadiene with hydroalkoxysilanes has been described using recyclable Pt nanoclusters as catalysts. ${ }^{19}$ Finally, ruthenium-catalyzed cationic polymerization of vinyl ethers using various hydrosilanes as initiator has been reported. ${ }^{20}$

Acyclic diene metathesis (ADMET) polymerization, as pioneered by Wagener et al., is also an effective route towards polyolefins incorporating alkoxysilyl groups on the terminus(i) or/and in their backbone. ${ }^{21}$ Hence, multi-substituted unsaturated polycarbosilanes have been prepared by one-pot nucleophilic substitution/ADMET polycondensation. ${ }^{22,23,24}$ Similarly, latent reactive processable elastomers constructed of carbosilane or carbosiloxane and polyether segments have been synthesized by using "chain-internal" and "chain-end" reactive methoxysilyl functionalities. ${ }^{25,26,27}$ Also, $\alpha, \omega$-bis(trialkylsilyl) telechelic polybutadienes with tailored molar mass have been synthesized via ADMET depolymerization of 1,4polybutadiene in the presence of 1,5-di(tert-butyldimethylsilyl)-3-hexene. ${ }^{28,29}$

Tandem ring-opening metathesis polymerization (ROMP)/cross-metathesis (CM) of cycloolefins in presence of functional olefins as chain-transfer agents (CTAs) is another 
methodology that provides large avenues for the synthesis of silyl-functionalized polyolefins. We have thus reported recently that the Ru-catalyzed ROMP/CM of cyclooctene (COE) using trialkoxysilyl-vinyl type compounds as CTAs effectively leads to the corresponding trialkoxysilyl-functionalized polyolefins; ${ }^{30}$ the process is, however, unselective as mixtures of $\alpha$-mono- and $\alpha, \omega$-difunctionalized linear polyolefins, along with lower amounts of isomerized and non-functionalized (linear and cyclic) polymers are formed.

On the other hand, the use of symmetrically disubstituted acyclic olefins as CTAs in $\mathrm{ROMP} / \mathrm{CM}$ process has been reported to form quite selectively $\alpha, \omega$-difunctionalized telechelic polymers (Scheme 1). ${ }^{31,32,33,34,35,36,37,38,39,40,41,42,43,44}$ For instance, dihydroxy telechelic polyenes have been obtained via the Ru-catalyzed ROMP/CM of COE, ${ }^{45} 1,5-$ cyclooctadiene $^{46,47}$ or 1,5-dimethyl-1,5-cycloctadiene ${ }^{48}$ using cis-1,4-bis(acetoxy)-2-butene as CTA, followed by deprotection of the acetoxy groups.

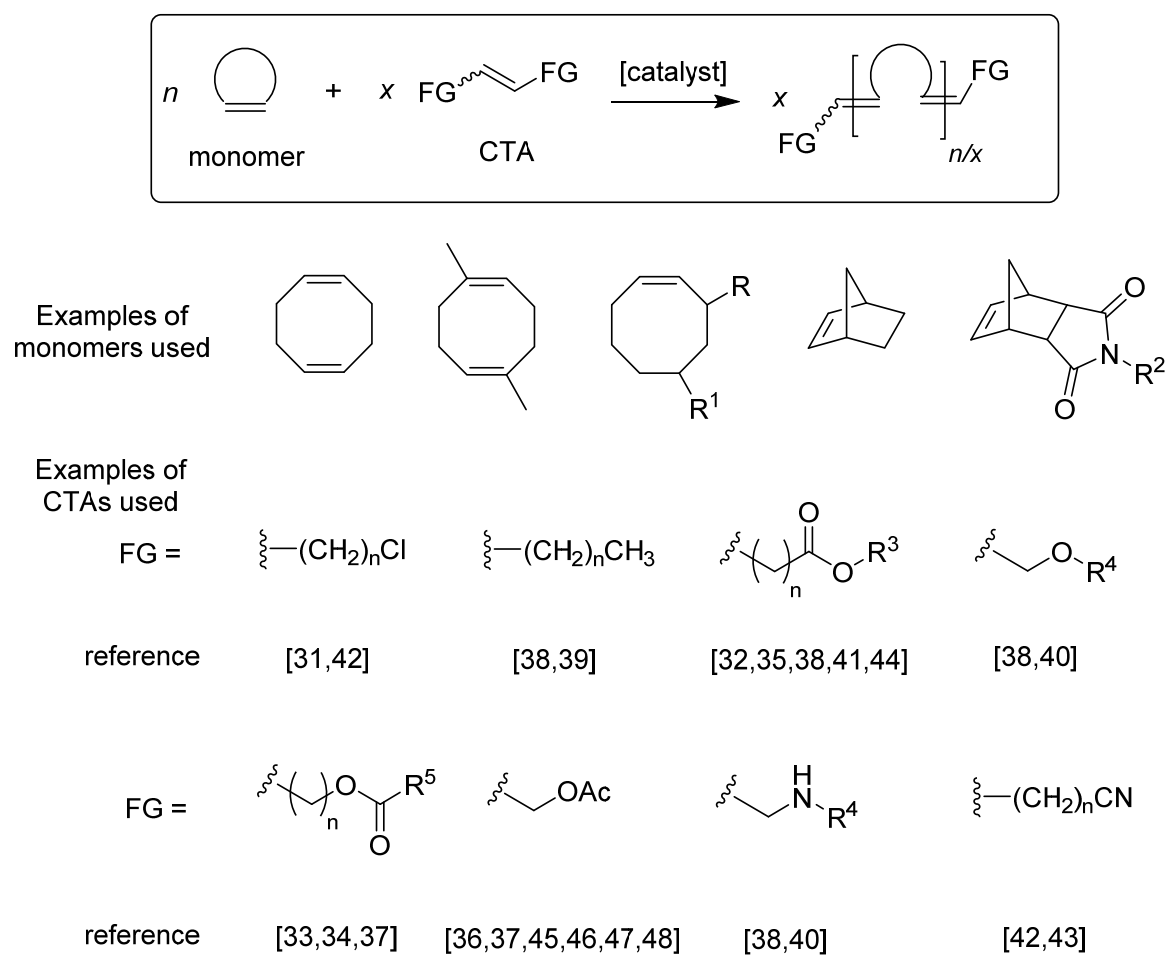

Scheme 1. Examples of preparation of $\alpha, \omega$-difunctionalized polyenes via $\mathrm{ROMP} / \mathrm{CM}$ of a cycloolefin using a symmetrically disubstituted olefin as chain-transfer agent (CTA). ${ }^{31-48}$ 
We now report on the first selective synthesis of $\alpha, \omega$-bis(trialkoxysilyl) telechelic polyolefins using several bis(trialkoxysilyl) olefins as CTAs in the Ru-catalyzed ROMP/CM of COE (Scheme 2). Different types of CTAs and catalysts have been investigated so as to optimize the overall catalytic productivity, selectivity and degree of control over the resulting telechelic macromolecules.

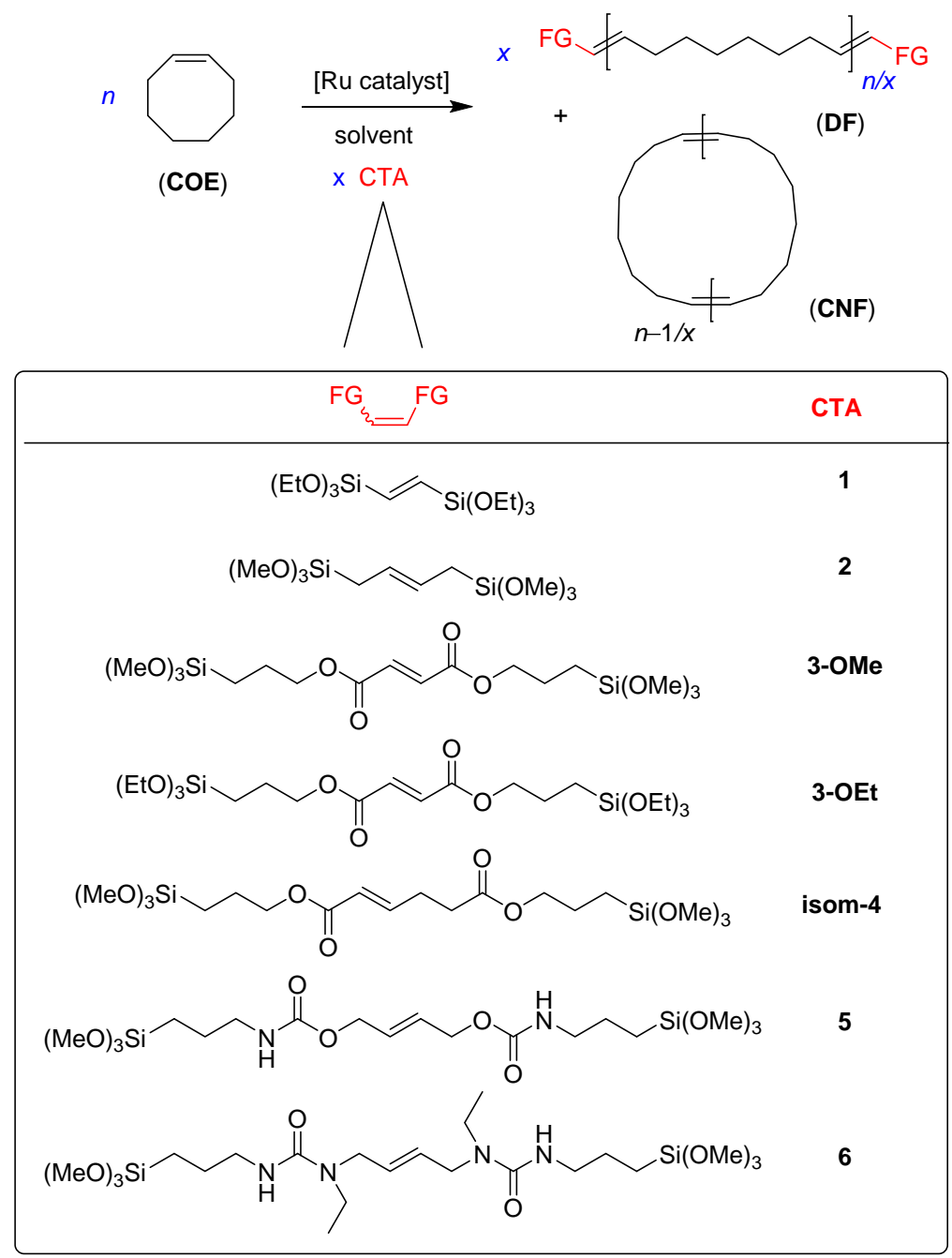

Scheme 2. Ruthenium-catalyzed tandem ROMP/CM of COE in presence of a bis(trialkoxysilyl) functional CTA, showing the two possible polymer types generated (FG: trialkoxysilyl functional group; DF: linear $\alpha, \omega$-difunctionalized polymer, CNF: cyclic nonfunctionalized polymer). 


\section{Results and Discussion}

Synthesis of trialkoxysilyl difunctional CTAs. Several bis(trialkoxysilyl) difunctional CTAs ( $\mathrm{FG}-\mathrm{CH}=\mathrm{CH}-\mathrm{FG})$ were selected for the present investigation (Scheme 2). Our main objective was to explore the impact of the functionality/spacer adjacent to the metathesis-active $\mathrm{C}=\mathrm{C}$ moiety onto the overall efficiency of the tandem $\mathrm{ROMP} / \mathrm{CM}$ process. Hence, in addition to CTA 1 and its bis-homologue $2,{ }^{49}$ which do not feature any functional group between the $\mathrm{C}=\mathrm{C}$ bond and the trialkoxysilyl functions, the fumarate-type CTAs 3$\mathbf{O M e}^{50}$ and 3-OEt, the bis-homologue hex-3-enedioate 4, and diurethane 5 and diurea $\mathbf{6}$ were targeted to assess electronic effects on the reactivity of the $\mathrm{C}=\mathrm{C}$ bond, as well as the functional compatibility with the Ru-based catalysts.

The synthesis of bis(3-trimethoxysilylpropyl) trans-hex-3-enedioate, CTA 4, was attempted by hydrosilylation of diallyl trans-hex-3-enedioate with trimethoxysilane under a variety of conditions, according to a patent procedure (Scheme 3). ${ }^{51}$ However, no reaction was observed using Crabtree's iridium catalyst, whilst mixtures of compounds, with incomplete hydrosilylation and isomerization of the double bond of trans-hex-3-enedioate into trans-hex-2-enedioate, were systematically recovered with Karstedt's platinum catalyst. Following a similar route as for the synthesis of CTA 3-OEt, the reaction of disodium hex-3enedioate with 3-chloropropyltrimethoxysilane in the presence of DMAP, allowed recovering the isomerized form (isom-4) of the targeted compound in an overall $60 \%$ yield (Scheme 3 ). Obviously, isomerization of the $\mathrm{C}=\mathrm{C}$ double bond drives the reaction towards the formation of the conjugated product. 


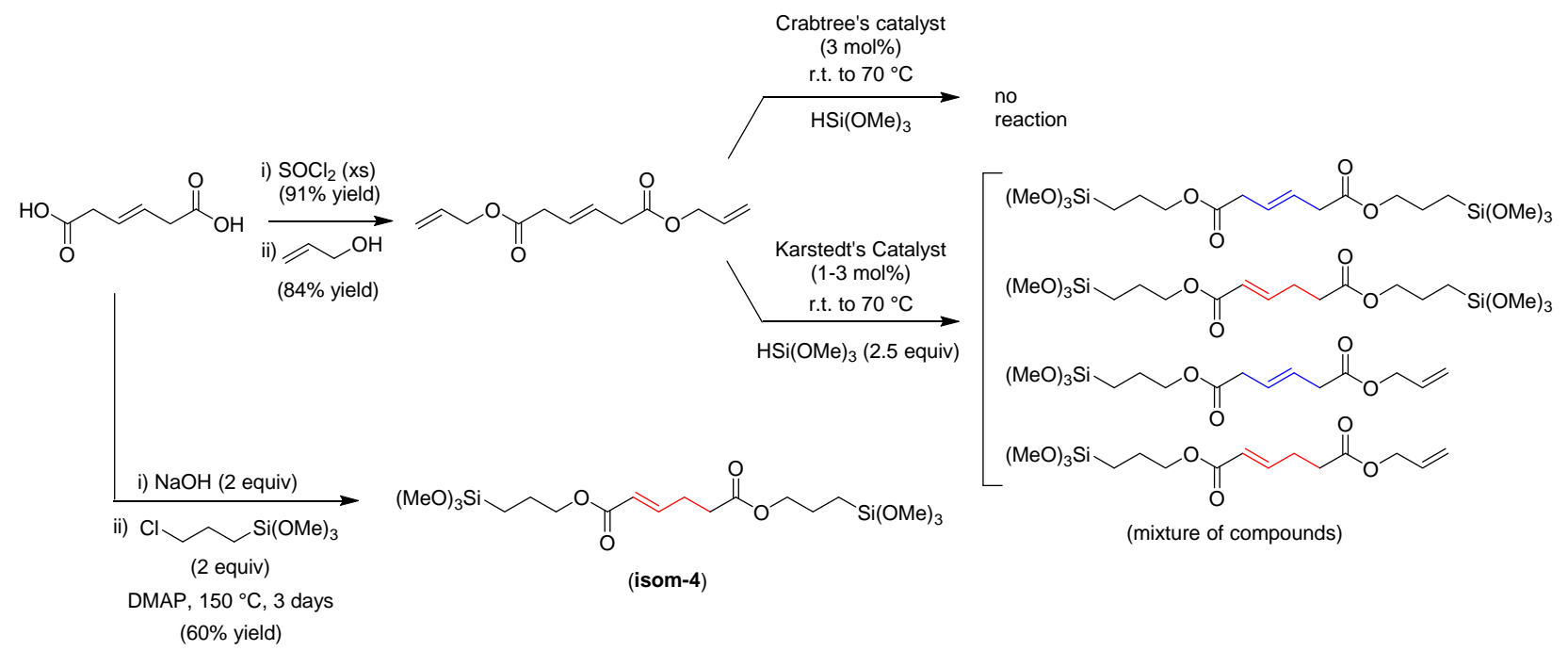

Scheme 3. Attempted synthesis of CTA 4 and isolation of isom-4.

The synthesis of diurethane CTA 5 was performed in a straightforward manner via addition of 2-butene-1,4-diol onto 3-(trimethoxysilyl)propyl isocyanate in bulk conditions (i.e., neat reagents). Similarly, diurea CTA 6 was recovered in quantitative yield upon reaction of $N, N^{\prime}$-diethyl-2-butene-1,4-diamine and 3-(trimethoxysilyl)propyl isocyanate (Scheme 4).

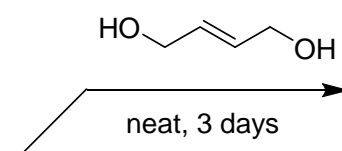

(98\%)<smiles>COCCCNC(=O)OC/C=C/COC(=O)NCCC[SiH2]OC</smiles>

(5)

$\mathrm{OCN}_{\mathrm{Si}(\mathrm{OMe})_{3}}$

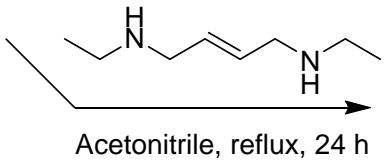

(99\%)<smiles>CCN(C/C=C/CN(CC)C(=O)NCCC[SiH2]OC)C(=O)NCCCOC</smiles>

(6)

Scheme 4. Synthesis of CTA 5 and 6.

Mechanism and outcome of tandem ROMP/CM process with difunctionalized CTAs.

The polymerization of a cycloolefin promoted by a ruthenium-alkylidene catalyst precursor in 
the presence of difunctional $\mathrm{CTAs}(\mathrm{FG}-\mathrm{CH}=\mathrm{CH}-\mathrm{FG})$ is assumed to proceed through a tandem one-pot ROMP/CM sequence. Scheme 5 depicts a deliberately simplified possible mechanistic scenario that accounts for the formation of $\alpha, \omega$-bis(trialkoxysilyl) telechelic polycycloolefin (DF) along with cyclic non-functionalized polymer (CNF), the only two (major and minor, respectively) products observed in this process. It is proposed that the ruthenium-alkylidene precursor $\mathbf{G} 2$ first initiates ROMP (a) that leads to I which contains a linear polymer chain, double-bonded to the metal center, with a terminal phenyl group. At this stage, competition shall take place between $\mathrm{CM}(\mathrm{b})$ and ring-closure metathesis (RCM) (c), the former functionalization process and the latter backbiting process leading to III (with regeneration of alkylidene species IV) and CNF (along with the Ru-activated linear polymer chain II structurally similar to I), respectively. Of note, CNF may reversibly ring-open (d). Then, DF is formed by CM between III and IV (f).

Supporting this mechanism, the formation of III was evidenced by NMR analysis (olefinic signals $\mathrm{H}^{7}, \mathrm{H}^{8}$ ) of the reaction mixture using a high catalyst loading ([COE $]_{0} /[\mathrm{CTA}$ 2 $]_{0} /[\mathbf{G 2}]_{0}=40: 2: 1, \mathrm{CH}_{2} \mathrm{Cl}_{2}, 40{ }^{\circ} \mathrm{C}$ ) (Figure 1; see Figures $\mathrm{S} 17$ and $\mathrm{S} 18$ in the Supp. Info. for the ${ }^{13} \mathrm{C}$ and COSY NMR spectra). The same signals were observed during the ROMP/CM of COE using other CTAs (e.g. alkyl fumarates), indicating that the formation of this species (III) is independent of the nature of CTA. Another important observation in support of this mechanism is that, for all $\mathrm{ROMP} / \mathrm{CM}$ reactions performed in this study, immediately following the addition of the catalyst onto the reagents, a rapid and important increase of the viscosity of the reaction medium was observed; this is consistent with the rapid formation of a high molar mass polymer via ROMP (process (a), refer also to the Experimental section). Then, a gradual decrease of the viscosity occurred, which supports the slower formation of shorter chains via CM with the CTA (process (b)). 


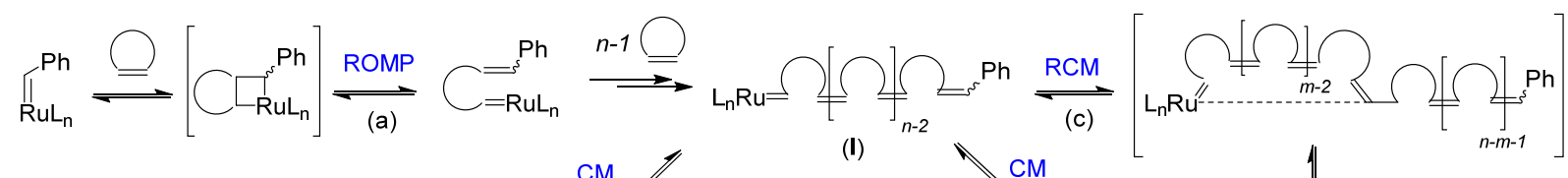

$$
\begin{aligned}
& \text { (b) }
\end{aligned}
$$

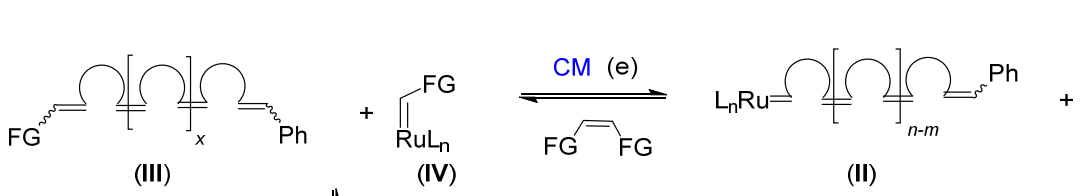

$$
\begin{aligned}
& C M \|(f) \\
& \text { (II) } \\
& \prod_{\mathrm{RuL}_{n}}^{\mathrm{Ph}}
\end{aligned}
$$
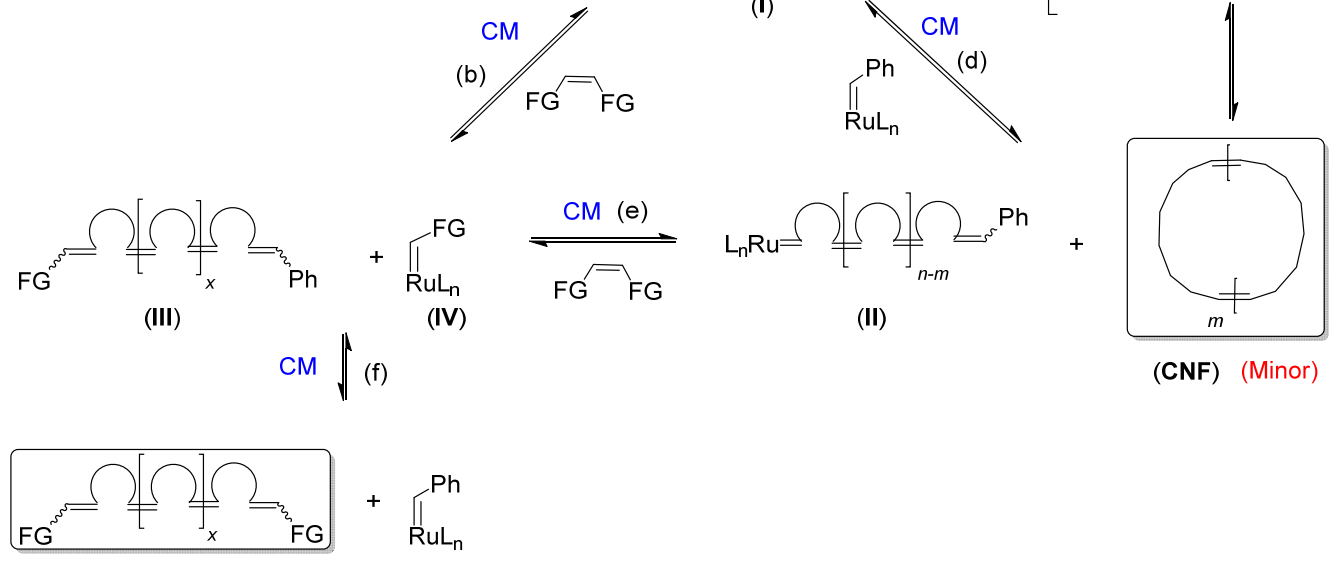

Scheme 5. Proposed simplified mechanism for the tandem ROMP/CM occurring during the polymerization of a cycloolefin mediated by a Ru-alkylidene catalyst precursor in the presence of a difunctional alkene CTA, accounting for the formation of both DF and CNF type polymers.

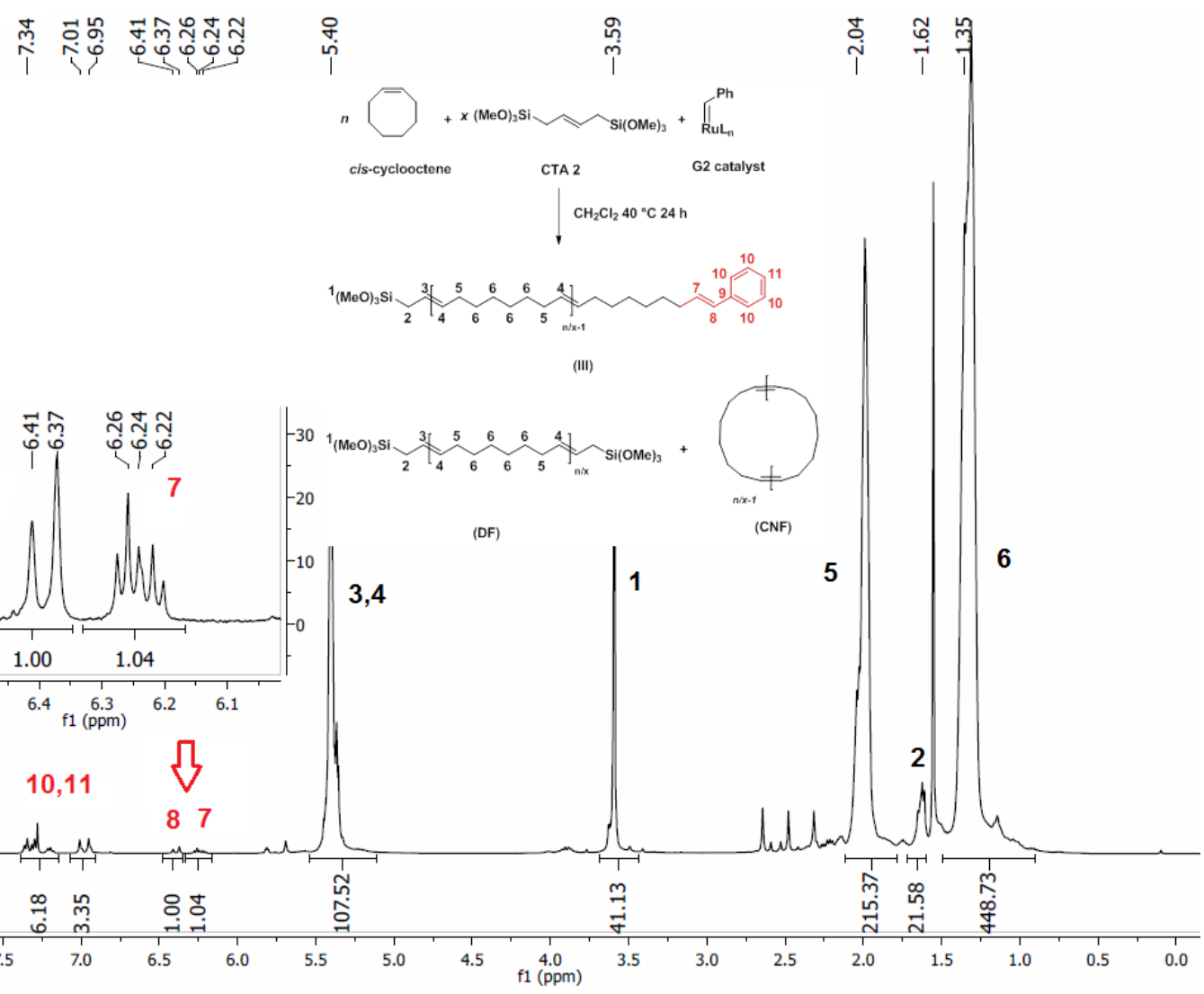


Figure 1. ${ }^{1} \mathrm{H}$ NMR spectrum $\left(400 \mathrm{MHz}, \mathrm{CDCl}_{3}, 298 \mathrm{~K}\right.$ ) of a crude PCOE sample prepared by ROMP/CM of COE/CTA 2.

\section{ROMP of COE using different trialkoxysilyl difunctional CTAs and different}

ruthenium catalysts. To identify and optimize the most efficient catalytic system in terms of selectivity and productivity, the ROMP/CM of COE was investigated using these difunctional CTAs and a series of ruthenium alkylidene catalysts (Scheme 2).

Reactivity of different CTAs using G2 catalyst. The various CTAs were first screened in the ROMP/CM of COE using Grubbs' $2^{\text {nd }}$ generation catalyst (G2). For comparison purposes, the reactions were performed under the same model conditions as those used with monofunctional CTAs, ${ }^{30}$ i.e. $[\mathrm{COE}]_{0} /[\mathrm{CTA}]_{0} /[\mathrm{G} 2]_{0}=2$ 000:50-100:1 in $\mathrm{CH}_{2} \mathrm{Cl}_{2}$ at $40{ }^{\circ} \mathrm{C}$. All reactions were at least duplicated and showed a quite good reproducibility of the conversion and molecular data $( \pm 10 \%)$. Representative results are summarized in Table 1 . 
Table 1. ROMP/CM of COE catalyzed by $\mathbf{G} 2$ in the presence of various CTAs. ${ }^{\text {a }}$

\begin{tabular}{|c|c|c|c|c|c|c|c|c|c|c|c|c|c|c|}
\hline \multirow[b]{2}{*}{ Entry } & \multirow[b]{2}{*}{$\begin{array}{l}{[\mathrm{COE}]_{0}} \\
\text { (equiv) }\end{array}$} & \multirow[b]{2}{*}{ CTA } & \multirow[b]{2}{*}{$\begin{array}{l}{[\mathrm{CTA}]_{0}} \\
\text { (equiv) }\end{array}$} & \multirow[b]{2}{*}{$\begin{array}{c}{[\mathbf{G 2}]_{0}} \\
\text { (equiv) }\end{array}$} & \multirow{2}{*}{$\begin{array}{l}\text { Reaction } \\
\text { time } \\
\text { (h) }\end{array}$} & \multirow{2}{*}{$\begin{array}{c}\text { COE } \\
\text { Conv. } \\
(\mathrm{mol} \%)\end{array}$} & \multirow{2}{*}{$\begin{array}{c}\text { CTA } \\
\text { Conv. } \\
\text { (mol\%) }\end{array}$} & \multicolumn{4}{|c|}{$\mathrm{DF}+\mathrm{CNF}^{\mathrm{c}}$} & \multicolumn{3}{|c|}{$\mathrm{CNF}^{\mathrm{c}}$} \\
\hline & & & & & & & & $\begin{array}{l}M_{\mathrm{n}, \text { theo }}{ }^{\mathrm{d}} \\
\left(\mathrm{g} \cdot \mathrm{mol}^{-1}\right)\end{array}$ & $\begin{array}{c}M_{\mathrm{n}, \mathrm{NMR}}{ }^{\mathrm{e}} \\
\left(\mathrm{g} \cdot \mathrm{mol}^{-1}\right)\end{array}$ & $\begin{array}{c}M_{\mathrm{n}, \mathrm{SEC}}^{\mathrm{f}} \\
\left(\mathrm{g} \cdot \mathrm{mol}^{-1}\right)\end{array}$ & $\bigoplus_{M}{ }^{\mathrm{f}}$ & $\begin{array}{c}X \\
(\mathrm{wt} \%)\end{array}$ & $\begin{array}{c}M_{\mathrm{n}, \mathrm{SEC}}{ }^{\mathrm{f}} \\
\left(\mathrm{g} \cdot \mathrm{mol}^{-1}\right)\end{array}$ & $\bigoplus_{M}{ }^{\mathrm{f}}$ \\
\hline $1^{i}$ & 2000 & 1 & 50 & 1 & 72 & 100 & 0 & - & - & - & - & - & - & - \\
\hline 2 & 2000 & 2 & 50 & 1 & 24 & 100 & 100 & 4400 & 5000 & 8100 & 1.9 & 4 & 13400 & 1.2 \\
\hline 3 & 2000 & 3-OMe & 100 & 1 & 24 & 100 & 19 & 12000 & 12800 & $n d$ & $n d$ & $n d$ & $n d$ & $n d$ \\
\hline 4 & 2000 & 3-OMe & 100 & 1 & 48 & 100 & 22 & 10000 & 9700 & $n d$ & $n d$ & $n d$ & nd & $n d$ \\
\hline 5 & 2000 & 3-OMe & 100 & $1+1^{g}$ & 62 & 100 & 32 & 6800 & 5700 & $n d$ & $n d$ & $n d$ & $n d$ & $n d$ \\
\hline 6 & 2000 & 3-OMe & 100 & $1+1+1^{\mathrm{g}}$ & 73 & 100 & 56 & 3900 & 3000 & 10300 & 1.5 & 13 & 13600 & 1.3 \\
\hline 7 & 2000 & 3-OEt & 100 & 1 & 24 & 100 & 14 & 16000 & 16400 & 20900 & 1.7 & 14 & 24000 & 1.3 \\
\hline 8 & 2000 & isom-4 & 100 & 1 & 24 & 100 & 60 & 4200 & 4000 & 24000 & 1.6 & 16 & 28400 & 1.4 \\
\hline 9 & 2000 & isom-4 & 100 & $1+1^{\mathrm{f}}$ & 48 & 100 & 94 & 2300 & 2500 & 10700 & 1.4 & 14 & 13100 & 1.3 \\
\hline 10 & 2000 & 5 & 100 & 1 & 24 & 100 & 100 & 2200 & 2100 & 4900 & 1.5 & 7 & 8200 & 1.2 \\
\hline $11^{\mathrm{i}}$ & 2000 & 6 & 50 & 1 & 72 & 100 & 0 & - & - & - & - & - & - & - \\
\hline $12^{\mathrm{h}}$ & 2000 & 2 & 50 & 1 & 24 & 100 & 100 & 4400 & 5100 & 13000 & 1.5 & 33 & 17400 & 1.3 \\
\hline $13^{\mathrm{h}}$ & 2000 & 5 & 50 & 1 & 24 & 100 & 100 & 4400 & 5900 & 13500 & 1.4 & 41 & 18000 & 1.2 \\
\hline
\end{tabular}

${ }^{a}$ Unless otherwise stated, reactions conducted in $\mathrm{CH}_{2} \mathrm{Cl}_{2}$ at $40{ }^{\circ} \mathrm{C}$ for $24 \mathrm{~h}$ (non-optimized reaction time) at $2.5 \mathrm{M} .{ }^{\mathrm{b}}$ Conversion of $\mathrm{COE}$ and $\mathrm{CTA}$ as determined by ${ }^{1} \mathrm{H}$ NMR analysis. ${ }^{\mathrm{c}} \mathbf{D F}=\alpha, \omega$-difunctionalized PCOE; $\mathbf{C N F}=$ cyclic non-functionalized PCOE; $X(\mathbf{C N F})(\mathrm{wt} \%)$ as determined by column chromatography of the crude polymer (see Experimental Section); $X(\mathbf{D F})=100-X(\mathbf{C N F}){ }^{\mathrm{d}}$ Theoretical molar mass value of the polymer calculated on the basis of the sole formation of $\mathbf{D F}$, from the relation $M_{\mathrm{n} \text {,theo }}=M_{\mathrm{COE}} \times\left([\mathrm{COE}]_{0} \times\right.$ Conv. $\left.\mathrm{COE}\right) /\left([\mathrm{CTA}]_{0} \times\right.$ Conv.CTA $) .{ }^{\mathrm{e}}$ Experimental molar mass determined by ${ }^{1} \mathrm{H}$ NMR analysis (refer to the Experimental Section). ${ }^{\mathrm{f}}$ Number-average molar mass $\left(M_{\mathrm{n}, \mathrm{SEC}}\right)$ and dispersity $\left(\bigoplus_{\mathrm{M}}=M_{\mathrm{w}} / M_{\mathrm{n}}\right)$ values determined by SEC vs. polystyrene standards (uncorrected $M_{\mathrm{n}}$ values) in THF at $30^{\circ} \mathrm{C}$.

${ }^{\mathrm{g}} \mathrm{A}$ second (and a third) equiv of catalyst was added after $24 \mathrm{~h}$ (and $24 \mathrm{~h}$ ). ${ }^{\mathrm{h}}$ Reactions performed at a lower concentration ( $0.25 \mathrm{M}$ vs. $2.5 \mathrm{M}$ (entries $\left.1-11\right)$ ). ${ }^{\mathrm{i}}$ Nonfunctionalized PCOE (linear NF and/or cyclic NF PCOE) was the only polymer recovered. $n d$ : not determined. 
The use of CTA 1 under these conditions led to full conversion of COE but the CTA was not converted at all, and non-functionalized $\mathrm{PCOE}^{52}$ was eventually the sole product recovered (Table 1, entry 1). In sharp contrast, when the reaction was performed in the presence of CTA 2, full conversion of both the monomer and the CTA, with quite selective formation of DF PCOE along with minor amounts of CNF, was observed (entry 2). In order to explain this striking difference in reactivity between these two CTAs, a control reaction was conducted using a mixture of $\mathbf{1}$ and $\mathbf{2}(25+25$ equiv); full conversion of $\mathrm{COE}$ and $\mathbf{2}$, along with the selective formation of DF PCOE terminated only with trimethoxysilylpropenyl groups was then observed, while $\mathbf{1}$ remained unreacted. This indicates that the $\mathbf{G} \mathbf{2}$ catalyst was not deactivated by possible impurities within $\mathbf{1}$, but that the latter CTA is ineffective for CM. This may be tentatively explained by the poor reactivity of putative alkylidene species of the $\mathrm{L}_{\mathrm{n}} \mathrm{Ru}=\mathrm{CHSi}(\mathrm{OR})_{3}$ type as compared to higher $\mathrm{L}_{\mathrm{n}} \mathrm{Ru}=\mathrm{CHCH}_{2} \mathrm{Si}(\mathrm{OR})_{3}$ analogues. In this regard, it is noteworthy to remind that the instability of Ru-alkylidene species $\mathrm{L}_{n} \mathrm{Ru}=\mathrm{CHR}$ bearing $\alpha$-substituents such as dichlorosilyl, isopropyl and tert-butyl, has been reported. $^{53,54,55}$

With CTAs 3-OMe, 3-OEt or isom-4, full conversion of COE was observed, yet with a low efficiency of the CM reaction, as evidenced by incomplete conversion of the CTA (entries 3-9). While prolonged reaction times had almost no effect, a higher conversion of CTAs 3 and isom-4 was achieved upon addition of extra equiv of fresh catalyst over the reaction course. Also, the selectivity was lower as compared to reactions performed with CTA 2, as ca. $15 \mathrm{wt} \%$ of CNF was systematically formed along DF. These observations suggest deactivation of the ruthenium active species, possibly by some impurities within CTAs 3-OMe, 3-OEt or isom-4. ${ }^{56}$

The $\mathrm{ROMP} / \mathrm{CM}$ of $\mathrm{COE}$ with diurethane 5 proceeded within $24 \mathrm{~h}$ with complete monomer and CTA consumption to afford essentially (93wt\%) DF PCOE (entry 10). Conversely, diurea CTA 6 proved unreactive and only non-functionalized $\mathrm{PCOE}^{52}$ was 
recovered (entry 11). The inefficiency of CTA 6 may arise from stereoelectronic effects affecting the reactivity of the $\mathrm{C}=\mathrm{C}$ bond, or from its capacity to inhibit the catalyst for $\mathrm{CM}$ due to its basic character.

These results evidence that the nature and purity of the CTAs are key factors for the efficiency of the ROMP/CM process. CTAs $\mathbf{2}$ and $\mathbf{5}$ are the most effective ones to access the targeted $\alpha, \omega$-difunctionalized telechelic polyolefins. In light of their ready availability ( 2 is synthesized in two steps while 5 is prepared quantitatively by simple addition of neat 2butene-1,4-diol onto 3-(trimethoxysilyl)propyl isocyanate), these CTAs were selected for the following studies.

It is well known that high dilution conditions favor the intramolecular RCM reaction. ${ }^{57,58}$ In order to better evidence the influence of the concentration on the selectivity of the polymer functionality, highly diluted reactions were performed (entries 12,13). As anticipated, the amount of CNF then increased significantly. For instance, using CTA 2, the amount of CNF increased from $4 \mathrm{wt} \%$ to $33 \mathrm{wt} \%$ when the concentration decreased from $2.5 \mathrm{M}$ to $0.25 \mathrm{M}$. Accordingly, to favor the intermolecular CM leading to DF PCOE, high concentrations $(2.5 \mathrm{M})$ were systematically used in the present study.

Structure of the polymers. The ${ }^{1} \mathrm{H}$ NMR spectrum of a representative crude PCOE prepared from CTA 2 at $[\mathrm{COE}]_{0} /[2]_{0} /[\mathbf{G} 2]_{0}=2$ 000:50:1 (Table 1, entry 2) is illustrated in Figure 2. It shows, besides the main chain signals $\left(\mathrm{H}^{5}-\mathrm{H}^{7}\right.$; note that the repeating COE units in DF and CNF are indistinguishable), the presence of diagnostic resonances for the trimethoxysilylmethylene end-groups of DF PCOE $\left(\mathrm{H}^{1}-\mathrm{H}^{2}\right)$. The ${ }^{13} \mathrm{C}\left\{{ }^{1} \mathrm{H}\right\} \mathrm{NMR}$ (Figure 3) and DEPT $135{ }^{13} \mathrm{C}\left\{{ }^{1} \mathrm{H}\right\}$ NMR spectra (see the Supp. Info., Figure S22) confirmed the presence of these functional groups of DF. On the other hand, the ${ }^{1} \mathrm{H}$ and ${ }^{13} \mathrm{C}$ NMR spectra of isolated CNF PCOE showed, as anticipated, only the signals for the main chain moieties and no signals for terminal functionalities (see the Supp. Info., Figures S21-S22). 


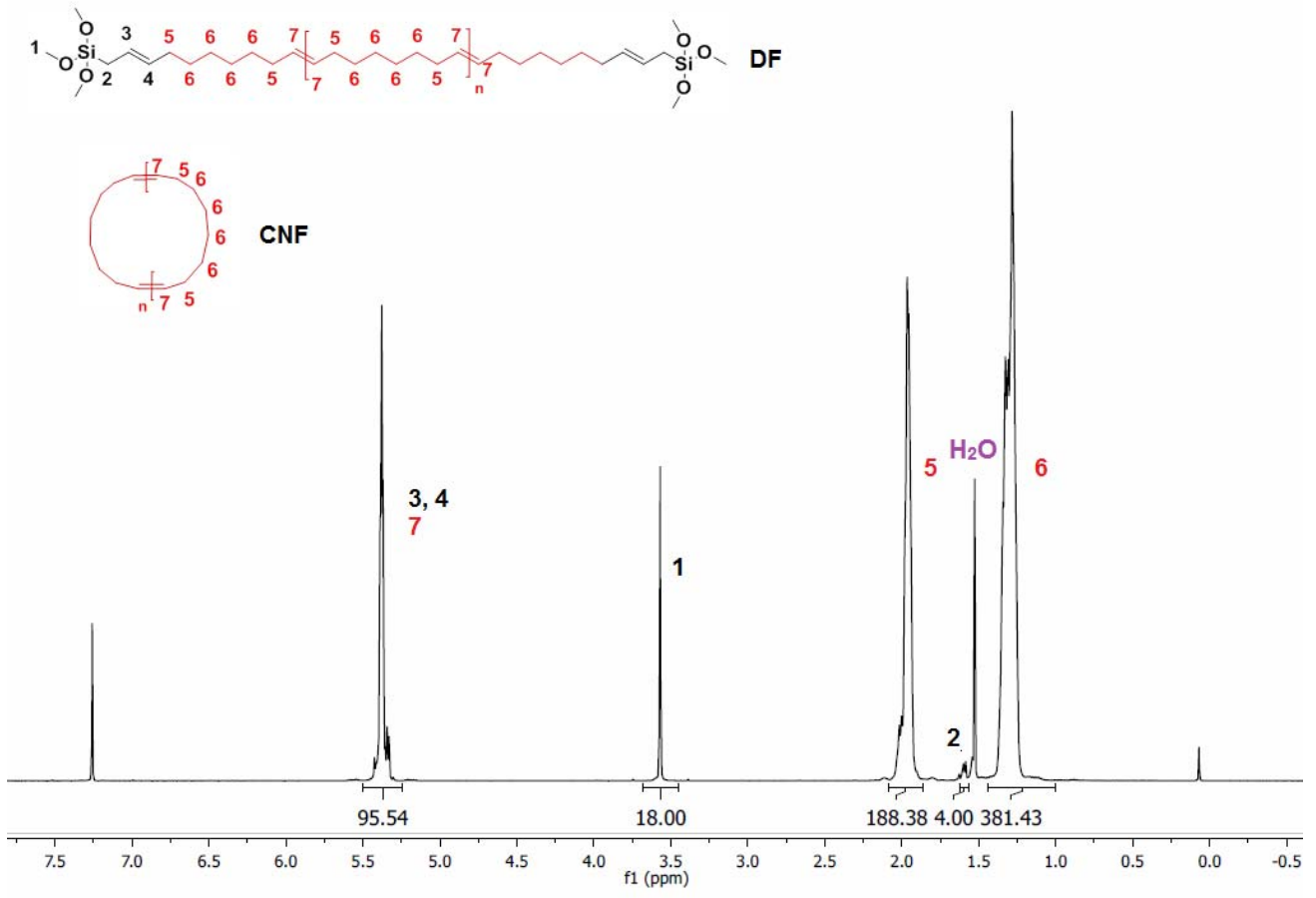

Figure 2. ${ }^{1} \mathrm{H}$ NMR spectrum $\left(400 \mathrm{MHz}, \mathrm{CDCl}_{3}, 298 \mathrm{~K}\right.$ ) of a crude PCOE sample prepared by ROMP/CM of COE/CTA 2 (Table 1, entry 2).

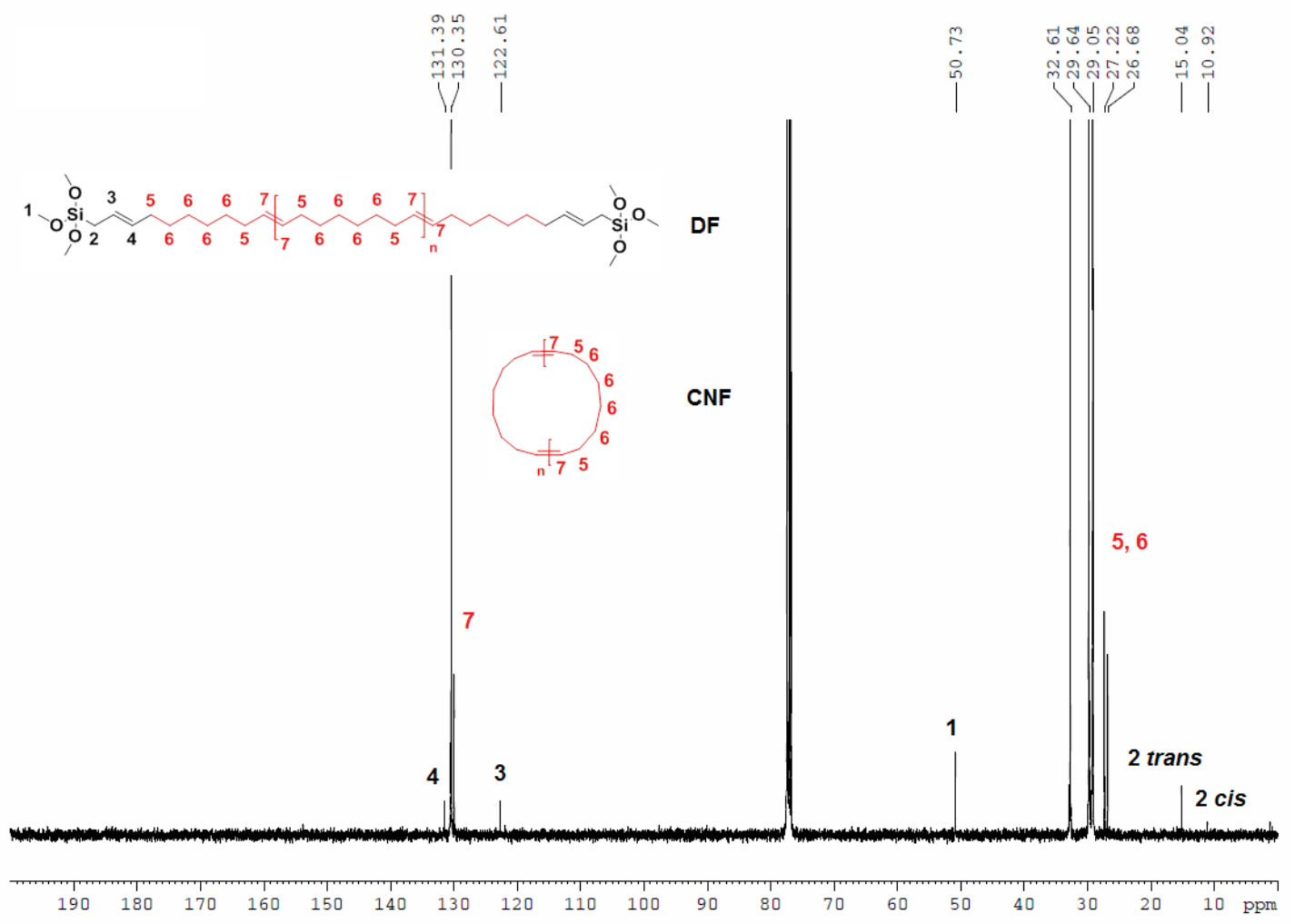

Figure 3. ${ }^{13} \mathrm{C}\left\{{ }^{1} \mathrm{H}\right\}$ NMR spectrum $\left(100 \mathrm{MHz}, \mathrm{CDCl}_{3}, 298 \mathrm{~K}\right)$ of a crude PCOE sample prepared by ROMP-CM of COE/CTA 2 (Table 1, entry 2). 
Closer insights into the polymer structure and in the nature of the functional endgroups were gained through MALDI-ToF mass spectrometry. These analyses were performed using either a sodium salt as cationizing agent of functional groups, thereby evidencing only DF (see the Supporting Information), or a silver salt as cationizing agent of $\mathrm{C}=\mathrm{C}$ bonds for the easy detection of both $\mathbf{D F}$ and $\mathbf{C N F}$ macromolecules (Figure 4). In fact, in the latter case, two distinct populations were observed: a major one corresponding to $\mathbf{D F}$ (with e.g. $m / z=1505.9$ g.mol ${ }^{-1}$ for $m=10 ; m / z_{\text {calcd }}=1506.1 \mathrm{~g} \cdot \mathrm{mol}^{-1}$ ) and a minor one matching CNF (with e.g. $m / z=1430.0$ g.mol ${ }^{-1}$ for $n=12 ; m / z_{\text {calcd }}=1430.2$ g.mol ${ }^{-1}$ ). 


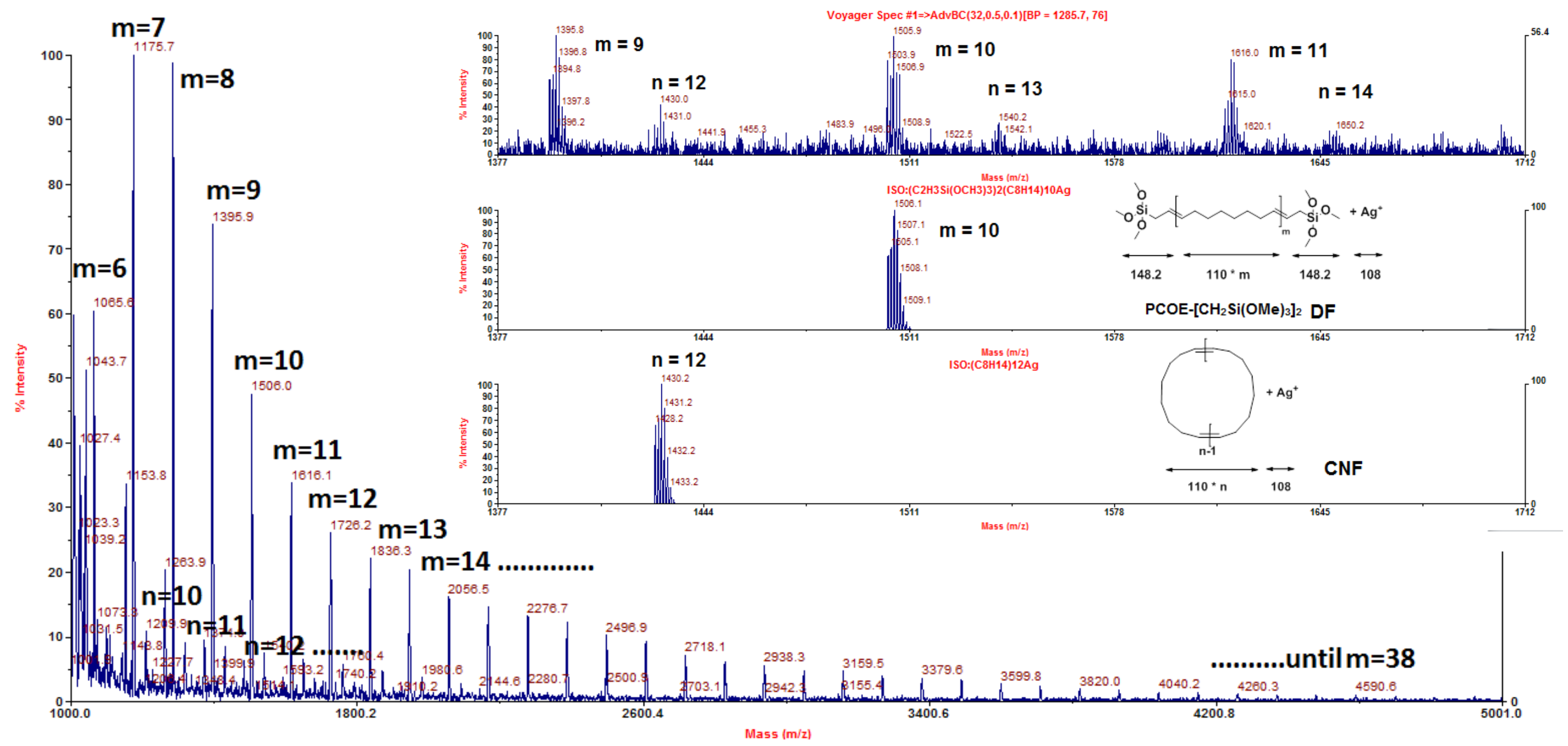

Figure 4. MALDI-ToF mass spectrum (DCTB matrix, $\mathrm{AgOCOCF}_{3}$ ) of a crude PCOE sample prepared by ROMP/CM of COE/CTA 2 (Table 1, entry 2), showing a mixture of DF and CNF PCOE; see top zoomed region and the corresponding middle and bottom simulations for $n=12$ and $m=10$, respectively. 
The PCOEs obtained using CTA isom-4 (Table 1, entry 8) were similarly characterized. Their ${ }^{1} \mathrm{H}$ NMR spectrum (Figure 5) clearly showed the presence of two terminal groups, differing by the position of the $\mathrm{C}=\mathrm{C}$ bond, due to the dissymmetric structure of the CTA. ${ }^{13} \mathrm{C}\left\{{ }^{1} \mathrm{H}\right\}$ NMR and MALDI-ToF MS data further confirmed the presence of those two different end-groups (see the Supp. Info. Figures S29-S31).

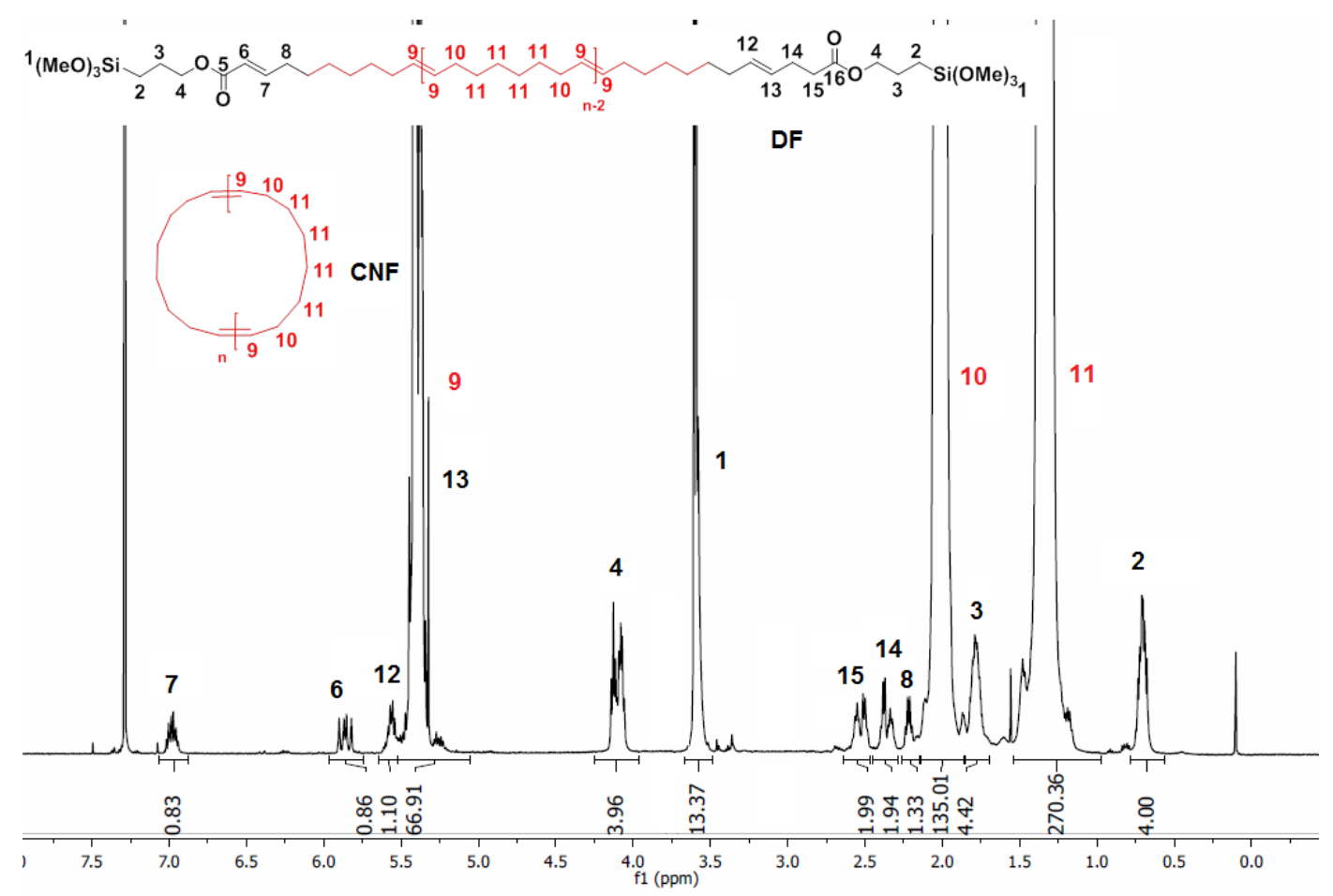

Figure 5. ${ }^{1} \mathrm{H}$ NMR spectrum $\left(500 \mathrm{MHz}, \mathrm{CDCl}_{3}, 298 \mathrm{~K}\right)$ of a crude PCOE sample prepared by ROMP/CM of COE/CTA 4 using G2 (Table 1, entry 8). Note that the formula, bearing two different terminal groups, only illustrates one of the three possible ones for DF.

The PCOEs obtained using the other CTAs (3-OMe, 3-OEt and 5) were also characterized by ${ }^{1} \mathrm{H},{ }^{13} \mathrm{C}\left\{{ }^{1} \mathrm{H}\right\}$ and ${ }^{1} \mathrm{H}-{ }^{13} \mathrm{C}$ HMQC NMR, FTIR, ESI and MALDI-ToF MS techniques, which corroborated their chemical structure, and in particular their chain endgroups (See the Supp. Info., Figures S23-S28, S32-36). 
Use of different ruthenium catalysts. Obviously, the catalyst is another important parameter to consider in $\mathrm{ROMP} / \mathrm{CM}$ reactions. Hence, in addition to Grubbs' $2^{\text {nd }}$ generation catalyst (G2), the efficiency of Grubbs' $3^{\text {rd }}$ generation catalyst $(\mathbf{G} 3),{ }^{59}$ Hoveyda-Grubbs's (HG2), ${ }^{60}$ Zhan's (Zhan), ${ }^{61}$ and of some OmegaCat catalysts $\left(\mathbf{M 7}_{3}\right.$-SIMes, M7 M $_{3}$ SIPr) ${ }^{62}$ (Figure 6), was compared in the ROMP/CM of COE using CTAs 2 and 5. Representative results (also from at least duplicated experiments) are summarized in Table 2. The influence of the solvent has been evidenced previously in ROMP/CM reactions using monofunctional CTAs. ${ }^{30,63}$ For the present reactions with difunctional CTAs, $\mathrm{CH}_{2} \mathrm{Cl}_{2}$ was also found to be the best solvent in terms of catalytic productivity and selectivity. Reactions performed in toluene showed systematically lower conversions; see for instance Table 2, entry 23.

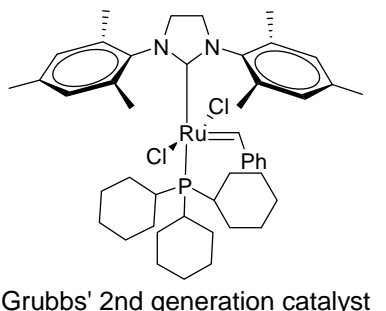

(G2)

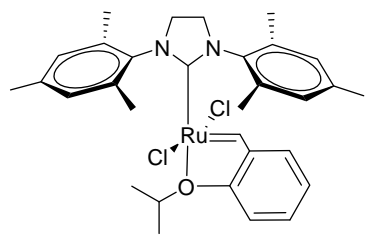

Hoveyda-Grubbs' 2nd generation catalyst (HG2)

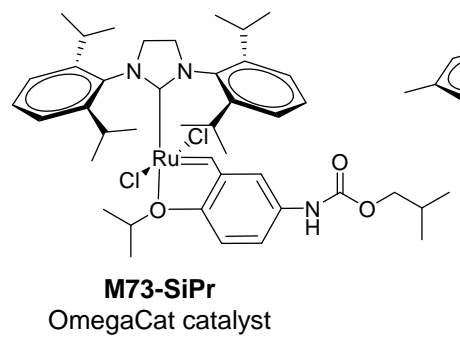

OmegaCat catalyst

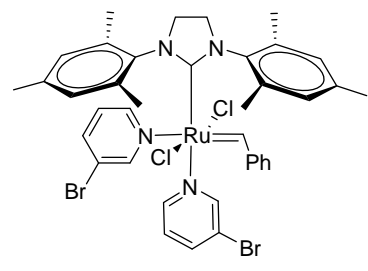

Grubbs' 3rd generation catalyst

(G3)

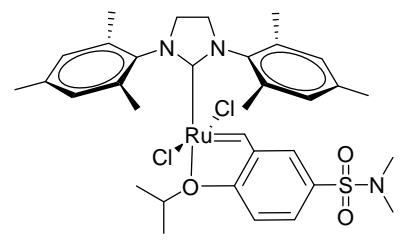

Zhan

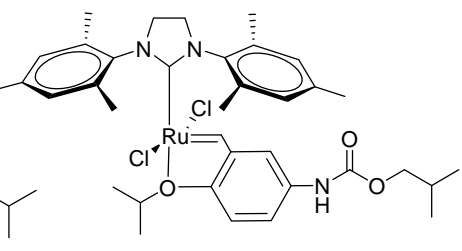

M73-SiMes

Figure 6. Olefin metathesis Ru-catalysts screened in this study. 
Table 2. $\mathrm{ROMP} / \mathrm{CM}$ of $\mathrm{COE} / \mathrm{CTAs}$ with various ruthenium catalysts. ${ }^{a}$

\begin{tabular}{|c|c|c|c|c|c|c|c|c|c|c|c|c|c|}
\hline \multirow[b]{2}{*}{ Entry } & \multirow[b]{2}{*}{$\begin{array}{l}{[\mathrm{COE}]_{0}} \\
\text { (equiv) }\end{array}$} & \multirow[b]{2}{*}{ CTA } & \multirow[b]{2}{*}{$\begin{array}{l}{[\mathrm{CTA}]_{0}} \\
\text { (equiv) }\end{array}$} & \multirow[b]{2}{*}{$\begin{array}{c}{[\mathrm{Ru}]} \\
\text { (1 equiv) }\end{array}$} & \multirow{2}{*}{$\begin{array}{c}\mathrm{COE} \\
\text { Conv. } \\
\text { (mol\%) }\end{array}$} & \multirow{2}{*}{$\begin{array}{c}\text { CTA } \\
\text { Conv. } \\
\text { (mol\%) }\end{array}$} & \multicolumn{4}{|c|}{$\mathrm{DF}+\mathrm{CNF}^{\mathrm{c}}$} & \multicolumn{3}{|c|}{ CNF } \\
\hline & & & & & & & $\begin{array}{c}M_{\mathrm{n}, \text { theo }}{ }^{\mathrm{d}} \\
\left(\mathrm{g} \cdot \mathrm{mol}^{-1}\right)\end{array}$ & $\begin{array}{l}M_{\mathrm{n}, \mathrm{NMR}}{ }^{\mathrm{e}} \\
\left(\mathrm{g} \cdot \mathrm{mol}^{-1}\right)\end{array}$ & $\begin{array}{c}M_{\mathrm{n}, \mathrm{SEC}}{ }^{\mathrm{f}} \\
\left(\mathrm{g} \cdot \mathrm{mol}^{-1}\right)\end{array}$ & $\bigoplus_{M}{ }^{\mathrm{f}}$ & $\begin{array}{c}X^{\mathrm{c}} \\
(\mathrm{wt} \%) \\
\end{array}$ & $\begin{array}{c}M_{\mathrm{n}, \mathrm{SEC}}{ }^{\mathrm{f}} \\
\left(\mathrm{g} \cdot \mathrm{mol}^{-1}\right)\end{array}$ & $\bigoplus_{M}{ }^{\mathrm{f}}$ \\
\hline 1 & 2000 & 2 & 50 & G2 & 100 & 100 & 4400 & 5400 & 8100 & 1.5 & 4 & 13400 & 1.2 \\
\hline 2 & 2000 & 2 & 50 & G3 & 100 & 100 & 4400 & 4900 & 8100 & 1.4 & 5 & 15100 & 1.2 \\
\hline 3 & 2000 & 2 & 50 & HG2 & 100 & 100 & 4400 & 5100 & 8500 & 1.6 & 3 & 11200 & 1.3 \\
\hline 4 & 2000 & 2 & 50 & Zhan & 100 & 100 & 4400 & 5100 & 7900 & 1.4 & 7 & 13000 & 1.3 \\
\hline 5 & 2000 & 2 & 50 & M7 $7_{3}$-SIPr & 100 & 100 & 4400 & 6400 & 14600 & 1.6 & 11 & 28100 & 1.2 \\
\hline 6 & 2000 & 2 & 50 & M7 $_{3}$-SIMes & 100 & 100 & 4400 & 5600 & 14000 & 1.8 & 9 & 23600 & 1.2 \\
\hline 7 & 8000 & 2 & 200 & G2 & 100 & 100 & 4400 & 5000 & 7600 & 1.7 & 8 & 15300 & 1.3 \\
\hline 9 & 16000 & 2 & 400 & G2 & 100 & 100 & 4400 & 4800 & 12300 & 1.8 & 11 & 23600 & 1.3 \\
\hline 10 & 48000 & 2 & 800 & G2 & 100 & 100 & 6600 & 6400 & 24000 & 1.6 & 12 & 35000 & 1.2 \\
\hline 11 & 48000 & 2 & 800 & G3 & 100 & 100 & 4400 & 4800 & 29200 & 1.7 & 14 & 45000 & 1.4 \\
\hline 12 & 48000 & 2 & 800 & HG2 & 100 & 100 & 6600 & 7200 & 39500 & 2.0 & 16 & 46000 & 1.4 \\
\hline 13 & 48000 & 2 & 800 & Zhan & 100 & 100 & 6600 & 6700 & 74500 & 1.8 & 21 & 77000 & 1.5 \\
\hline 14 & 48000 & 2 & 800 & $\mathrm{M7}_{3}-\mathrm{SIPr}$ & 100 & 100 & 6600 & 8900 & 104000 & 2.0 & 27 & 136000 & 1.7 \\
\hline 15 & 48000 & 2 & 800 & M7-SIMes & 100 & 100 & 6600 & 9200 & 40000 & 1.8 & 23 & 50000 & 1.4 \\
\hline 16 & 50000 & 5 & 1250 & G2 & 100 & 100 & 4400 & 4600 & 34000 & 1.5 & 8 & 60000 & 1.2 \\
\hline $17^{\mathrm{g}}$ & 50000 & $5^{g}$ & 1250 & G2 & 100 & 100 & 4400 & 5100 & 16000 & 2.0 & 10 & 31000 & 1.3 \\
\hline 18 & 50000 & 5 & 1250 & HG2 & 100 & 100 & 4400 & 5400 & 17700 & 1.5 & 18 & 34200 & 1.3 \\
\hline 19 & 50000 & 5 & 1250 & G3 & 100 & 100 & 4400 & 5100 & 21600 & 1.7 & 13 & 45400 & 1.5 \\
\hline 20 & 100000 & 5 & 5000 & G2 & 86 & 100 & 1900 & 2400 & 25400 & 2.0 & 36 & 50000 & 1.4 \\
\hline 21 & 100000 & 5 & 5000 & HG2 & 95 & 100 & 2100 & 2100 & 19400 & 1.6 & 21 & 54700 & 1.3 \\
\hline 22 & 100000 & 5 & 5000 & G3 & 53 & 0 & - & - & $n d$ & $n d$ & 100 & $n d$ & $n d$ \\
\hline $23^{\mathrm{h}}$ & 100000 & 5 & 5000 & G2 & 51 & 0 & - & - & $n d$ & $n d$ & 100 & $n d$ & $n d$ \\
\hline
\end{tabular}

${ }^{a}$ Unless otherwise stated, reactions conducted in $\mathrm{CH}_{2} \mathrm{Cl}_{2}$ at $40{ }^{\circ} \mathrm{C}$ for $24 \mathrm{~h}$ (non-optimized reaction time) at $2.5 \mathrm{M}$. ${ }^{\mathrm{b}}$ Conversion of $\mathrm{COE}$ and $\mathrm{CTA}$ as determined by ${ }^{1} \mathrm{H}$ NMR analysis. ${ }^{\mathrm{c}} \mathbf{D F}=\alpha, \omega$-difunctionalized PCOE; $\mathbf{C N F}=$ cyclic non-functionalized PCOE; $X(\mathbf{C N F})(\mathrm{wt} \%)$ as determined by column chromatography of the crude polymer (see Experimental Section); $X(\mathbf{D F})=100-X(\mathbf{C N F}) .{ }^{\mathrm{d}}$ Theoretical molar mass value of the polymer calculated from $M_{\mathrm{n} \text {,theo }}=M_{\mathrm{COE}} \times\left([\mathrm{COE}]_{0} \times\right.$ Conv. $\left.\mathrm{COE}\right) /\left([\mathrm{CTA}]_{0} \times\right.$ Conv.CTA $)$, on the basis of the formation of only DF, i.e. without taking into account any CNF. ${ }^{\mathrm{e}}$ Experimental molar mass value determined by ${ }^{1} \mathrm{H}$ NMR analysis (see Experimental Section). ${ }^{\mathrm{f}}$ Number-average molar mass $\left(M_{\mathrm{n}, \mathrm{SEC}}\right)$ and dispersity $\left(D_{\mathrm{M}}=\right.$ $M_{\mathrm{w}} / M_{\mathrm{n}}$ ) values determined by SEC $v s$. polystyrene standards (uncorrected $M_{\mathrm{n}}$ values) in THF at $30^{\circ} \mathrm{C} .{ }^{\mathrm{g}}$ Synthesis of CTA 5 and ROMP/CM of COE conducted in one-pot (Scheme 6). ${ }^{\mathrm{h}}$ Reaction performed in toluene. 
Productivity of the catalysts. Using CTA 2 under our standard conditions, the formation of DF PCOE along with minor amounts of CNF PCOE (vide infra) was observed with all ruthenium catalysts (Table 2, entries 1-6). Increasing the COE and CTA 2 loading up to 48000 and 800 equiv, respectively, confirmed a high productivity of all ruthenium catalysts with effective turnover numbers (TONs) up to 48000 (Table 2, entries 7-15).

Full conversion of the reagents was also observed using CTA 5 with G2, G3 and HG2 catalysts at $[\mathrm{COE}]_{0} /[5]_{0} /[\mathrm{Ru}]_{0}=50000: 1250: 1$ (entries 16-19). Further increasing the monomer and CTA loads to 100000 and 5000 equiv, respectively, enabled differentiating the ultimate abilities of these catalysts. G2 gave $86 \mathrm{~mol} \%$ conversion of COE, while $95 \mathrm{~mol} \%$ conversion was reached with HG2, both with full conversion of the CTA (entries 20, 21). On the other hand, G3 led to only $50 \mathrm{~mol} \%$ of conversion of COE and no conversion of the CTA under these conditions (entry 22).

DF/CNF Selectivity of the catalysts. The amount of CNF PCOE in the crude polymer sample was quantified after trapping the DF polymer onto acidified silica. With CTA 2, at relatively low reagent loadings $\left([\mathrm{COE}]_{0} /[2]_{0} /[\mathrm{Ru}]_{0}=2000: 50: 1\right)$, the mixture of polymers obtained from all the ruthenium catalysts contained $89-97$ wt $\%$ of DF; catalysts G2, G3, HG2 and Zhan's were more selective (93-97wt\% DF) than those from OmegaCat $(89-91 w t \%$ DF) (entries 1-6). Larger amounts of CNF PCOE (8-27wt\%) were recovered at higher reagent loads. This probably reflects partial catalyst decay under such demanding conditions, and the difficulty to complete CM.

The same trends were observed with CTA 5: at $[\mathrm{COE}]_{0} /[5]_{0} /[\mathrm{Ru}]_{0}=50$ 000:1 250:1 with G2, HG2 and G3 catalysts, the amount of CNF remained low (8-18wt\%) (entries 16-19). With a monomer and CTA load of 100000 and 5000 equiv, respectively, the amount of CNF increased up to $36 \mathrm{wt} \%$ with G2 catalyst but remained at a reasonable $21 \mathrm{wt} \%$ with HG2 (entries 20, 21). Overall, these data indicated that HG2 is the most productive (robust) and selective out of the different catalysts investigated for this process. 
Interestingly, the reaction with 5 could be performed in a simple one-pot protocol, by generating the latter CTA in situ (Scheme 6). Hence, COE, 2-butene-1,4-diol and 3(trimethoxysilyl)propyl isocyanate were placed in a flask at $90{ }^{\circ} \mathrm{C}$ for $72 \mathrm{~h}$ under neat conditions to generate CTA 5. Then, the reaction mixture was cooled to $40{ }^{\circ} \mathrm{C}$ and a solution of $\mathbf{G} 2$ in $\mathrm{CH}_{2} \mathrm{Cl}_{2}$ was added in to promote the $\mathrm{ROMP} / \mathrm{CM}$ process. This reaction protocol advantageously led to the same results as the reactions carried out with prior isolation of CTA 5 (entries 16 vs. 17).

$\mathrm{n}$
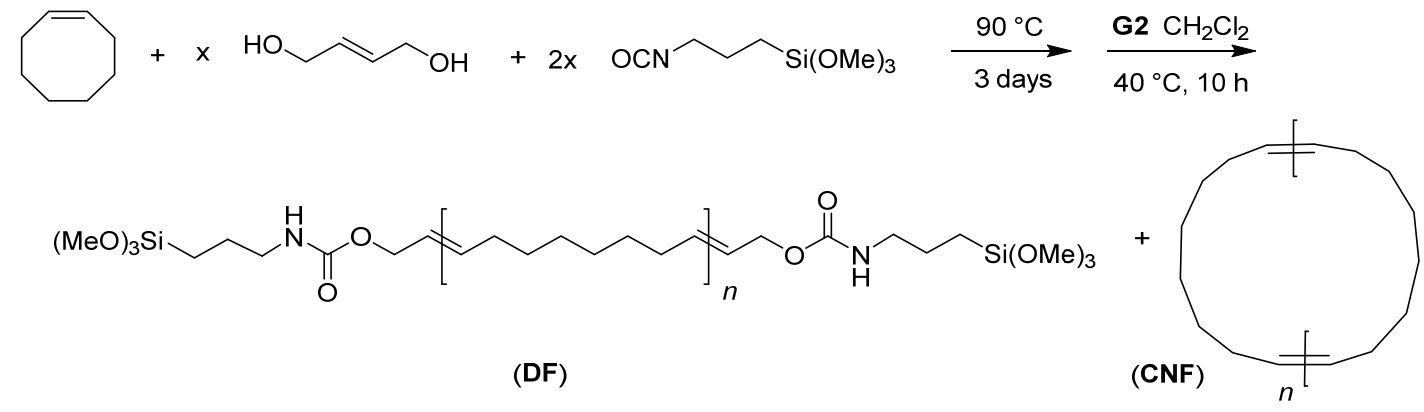

Scheme 6. Tandem ROMP/CM of COE/5 catalyzed by $\mathbf{G} 2$ catalyst using a one-pot protocol including the in situ generation of CTA 5 (Table 2, entry 17).

Molar masses of the polymers. The $M_{\mathrm{n}, \mathrm{NMR}}$ values were determined from the integral ratio of the signals of end-groups' hydrogens to the internal olefin hydrogens (vide supra, Figures 1 and 4). The $M_{\mathrm{n}, \mathrm{NMR}}$ values of all polymers matched quite well the theoretical molar mass values (calculated without taking into account any CNF, a reasonable hypothesis considering the actual low amounts) (Tables 1 and 2). The dispersity of the crude polymers were all monomodal and moderately large $\left(\bigoplus_{M}=1.4-2.0\right)$, as classically reported for ROMP/CM reactions. $^{40,64,65}$ The uncorrected $M_{\mathrm{n}}$,SEC values of the DF polymers were always higher than the corresponding $M_{\mathrm{n}, \mathrm{NMR}}$ and $M_{\mathrm{n}}$,theo values; this most likely arises from their different hydrodynamic volumes as compared to polystyrene standards used for calibration. On the other hand, the difference between the $M_{\mathrm{n}, \mathrm{SEC}}$ and the corresponding $M_{\mathrm{n}, \mathrm{NMR}}$ values is much 
more significant for polymers recovered from reactions performed at higher monomer loadings ( $>5000$ equiv), although the same final $M_{\mathrm{n}}$ value was targeted. We noted also that the $M_{\mathrm{n}}$,SEC values slightly decrease by adding more catalyst: in a reaction performed at $[\mathrm{COE}]_{0} /[5]_{0} /[\mathbf{G} 2]_{0}=50000: 1250: 1$, the $M_{\mathrm{n}}, \mathrm{SEC}$ value of the crude polymer $(93 \mathrm{wt} \% \mathbf{D F})$ observed after $24 \mathrm{~h}$ decreased from 26500 down to 20100 and 17400 g.mol ${ }^{-1}\left(\bigoplus_{M}=1.4\right.$ for all) upon adding, a second (after $24 \mathrm{~h}$ ) and a third (after $48 \mathrm{~h}$ ) equiv of G2 catalyst, respectively. These observations suggest that, in reactions carried out at high reagent loadings, the $\mathrm{CM}$ process does not reach equilibrium (due to low amounts of active $\mathrm{Ru}$ species), leaving some macromolecules of high molar mass that are detected in SEC analysis (but not in NMR that simply provides an average $M_{\mathrm{n}}$ value without dispersity information).

\section{Conclusions}

The ROMP/CM of COE with several bis(trialkoxysilyl) difunctionnal alkenesas CTAs in the presence of Ru-alkylidene catalysts offers an effective access to well-defined $\alpha, \omega$ bis(trialkoxysilyl) telechelic PCOEs (DF). The only side-product is the cyclic non-functional PCOE (CNF), which is always formed in minor quantities (typically 10-20wt\%). The use of such difunctional CTAs is much more selective than that of monofunctional analogues, such as trialkoxysilyl acrylates, which lead to a structural diversity of polyolefins out of which DF is a minor component. ${ }^{30}$

The productivity and selectivity of the catalytic process depend much on the nature of the CTA and catalyst. Out of the six CTAs investigated, 2 and 5 allowed a high productivity with remarkable turnover numbers up to $95000 \mathrm{~mol}(\mathrm{COE}) \cdot \mathrm{mol}(\mathrm{Ru})^{-1}$ and 5000 $\operatorname{mol}(\mathrm{CTA}) \cdot \operatorname{mol}(\mathrm{Ru})^{-1}$; CTA 5 is easy to prepare, and can even be conveniently generated in situ in the one-pot ROMP/CM. In contrast, 3-OMe, 3-OEt, 4 and 6 proved ineffective, since, in their presence, the $\mathbf{G} 2$ catalyst most likely deactivated before the CM process was completed; it is still unclear whether this deactivation in inherent to the structure of these 
CTAs (and of the corresponding Ru-alkylidene species derived thereof) or from the presence of unidentified residual impurities. G2 and HG2 were found to be the most productive and selective catalysts, in light of their high TONs and low amounts of CNF polymer formed.

All of these features allow envisaging the industrial production of trialkoxysilyl difunctionalized polyolefins. The trialkoxysilyl groups can be engaged in crosslinking reactions under the action of moisture to form siloxanes, which ensure good sealing properties. Preliminary investigations show that the rate of crosslinking of these DF PCOE is twice higher than that of the corresponding monofunctionalized polymers. Also, the viscosity of the DF materials can be controlled by adjusting the nature of the main chain segments, notably by copolymerizing instead of homopolymerizing cycloolefins. Detailed results along these lines will be reported in due course.

\section{Experimental Section}

Materials. All catalytic experiments were performed under inert atmosphere (argon, $<3 \mathrm{ppm}$ $\mathrm{O}_{2}$ ) using standard Schlenk line and glove box techniques. Cyclooctene $(\mathrm{COE})$ and $\mathrm{CH}_{2} \mathrm{Cl}_{2}$ (stabilized with amylene) were dried and distilled over $\mathrm{CaH}_{2}$ before use. Grubbs' $2^{\text {nd }}-$ generation catalyst $(\mathbf{G} 2)$, Grubbs' $3^{\text {rd }}$ generation catalyst (G3), Hoveyda-Grubbs' $2^{\text {nd }}$ generation catalyst (HG2), Zhan's catalyst (Zhan) were purchased from Sigma-Aldrich and used as received. Catalysts $\mathbf{M} 7_{3}$-SIMes and $\mathbf{M} 7_{3}$-SIPr were provided by OmegaCat Co. and used as received. 1,2-Bis(triethoxysilyl)ethene (1; Aldrich) and bis(3-trimethoxysilylpropyl) fumarate (3-OMe, Gelest) were purchased and used as received. CTAs $2^{49}$ (Figures S1-S2) and $3-\mathbf{O E t}^{50}$ (Figures S3-S4) were synthesized according to the reported literature procedures.

Instrumentation and measurements. ${ }^{1} \mathrm{H}(500,400 \mathrm{MHz})$ and ${ }^{13} \mathrm{C}\left\{{ }^{1} \mathrm{H}\right\}(125,100 \mathrm{MHz})$ NMR spectra were recorded on Bruker Avance AM 500 and AM 400 spectrometers at $23{ }^{\circ} \mathrm{C}$ in $\mathrm{CDCl}_{3}$. Chemical shifts $(\delta)$ are reported in ppm and were referenced internally relative to 
tetramethylsilane $(\delta 0 \mathrm{ppm})$ using the residual ${ }^{1} \mathrm{H}$ and ${ }^{13} \mathrm{C}$ solvent resonances. A relaxation delay of $1 \mathrm{~s}$ and $1.5 \mathrm{~s}$ was used during the acquisition to afford "quantitative" ${ }^{1} \mathrm{H}$ and ${ }^{13} \mathrm{C}\left\{{ }^{1} \mathrm{H}\right\}$ NMR spectra, respectively.

Monomer conversions were determined from ${ }^{1} \mathrm{H}$ NMR spectra of the crude polymer sample, from the integration (Int.) ratio Int.Polymer./[nt.Polymer + Int.monomer], using the methine hydrogens ( $-\mathrm{CH}=\mathrm{CH}-: \delta 5.30 \mathrm{ppm}$ for PCOE, and $5.66 \mathrm{ppm}$ for $\mathrm{COE})$.

The molar mass values of the polymers samples were determined by ${ }^{1} \mathrm{H}$ NMR analysis in $\mathrm{CDCl}_{3}\left(M_{\mathrm{n}, \mathrm{NMR}}\right)$ from the integral ratio of the signals of end-groups hydrogens (typically $\delta$ $\left.3.56\left(\mathrm{H}^{1}\right)\right)$ to internal olefin hydrogens $\left(\delta 5.38\left(\mathrm{H}^{7}\right)\right)$ (see Figure 4$)$.

The average molar mass $\left(M_{\mathrm{n}, \mathrm{SEC}}\right)$ and dispersity $\left(\bigoplus_{\mathrm{M}}=M_{\mathrm{w}} / M_{\mathrm{n}}\right)$ values were determined by size exclusion chromatography (SEC) in $\mathrm{THF}$ at $30^{\circ} \mathrm{C}$ (flow rate $=1.0$ $\mathrm{mL} \cdot \mathrm{min}^{-1}$ ) on a Polymer Laboratories PL50 apparatus equipped with a refractive index detector and a set of two ResiPore PLgel $3 \mu \mathrm{m}$ MIXED-E $300 \times 7.5 \mathrm{~mm}$ columns. The polymer samples were dissolved in THF $\left(2 \mathrm{mg} \cdot \mathrm{mL}^{-1}\right)$. All elution curves were calibrated with 12 monodisperse polystyrene standards $\left(M_{\mathrm{n}}\right.$ range $\left.=580-380,000 \mathrm{~g} \cdot \mathrm{mol}^{-1}\right) \cdot M_{\mathrm{n}, \mathrm{SEC}}$ values of polymers were uncorrected for their possible difference in hydrodynamic volume vs. polystyrene. The SEC traces of the polymers all exhibited a monomodal and symmetrical peak.

FTIR spectra were recorded on a IR Affinity-1 SHIMADZU spectrometer equipped with a PIKE technologies GladiATR device for measurements.

MALDI-ToF mass spectra were recorded at the CESAMO (Bordeaux, France) on a Voyager mass spectrometer (Applied Biosystems) equipped with a pulsed $\mathrm{N}_{2}$ laser source (337 nm, 4 ns pulse width) and a time-delayed extracted ion source. Spectra were recorded in the positive-ion mode using the reflectron mode and with an accelerating voltage of $20 \mathrm{kV}$. A freshly prepared solution of the polymer sample in THF (HPLC grade, $10 \mathrm{mg} \cdot \mathrm{mL}^{-1}$ ), a saturated solution of trans-2-[3-(4-tert-butylphenyl)-2-methyl-2-propenylidene]malononitrile 
(DCTB, $10 \mathrm{mg})$ in THF (1 mL, HPLC grade) were prepared. A MeOH solution of the cationisation agent (NaI or AgTFA, $10 \mathrm{mg} \cdot \mathrm{mL}^{-1}$ ) was also prepared. The solutions were combined in a 10:1:1 $v / \nu$ of matrix-to-sample-to-cationisation agent. $1-2 \mu \mathrm{L}$ of the resulting solution were deposited onto the sample target and vacuum-dried.

HRMS data were recorded with a Bruker MicrOTOF-Q II mass spectrometer equipped with an ESI (Electrospray Ionization) source in the positive mode. The acceleration voltage was $4-5 \mathrm{kV}$.

Synthesis of CTA isom-4. A $100 \mathrm{~mL}$ round-bottom flask, equipped with a magnetic stir bar, was charged with trans-3-hexenedioic acid (2.00 g, $13.9 \mathrm{mmol}), \mathrm{NaOH}(1.11 \mathrm{~g}, 27.8$ mmol) and distilled water $(10.0 \mathrm{~mL})$. The mixture was placed at $40^{\circ} \mathrm{C}$ for $10 \mathrm{~h}$. Disodium trans-3-hexenedioate $(2.60 \mathrm{~g})$ was obtained as a white powder upon removing water under vacuum. Under argon atmosphere, a $100 \mathrm{~mL}$ round-bottom Schlenk flask, equipped with a magnetic stir bar, was charged with 3-chloropropyltrimethoxysilane (5.52 g, $5.2 \mathrm{~mL}, 27.8$ mmol). Disodium trans-3-hexenedioate (2.60 g, $13.8 \mathrm{mmol})$ and DMAP (68 mg, $0.56 \mathrm{mmol})$ were then added into the stirred mixture. Once the addition was completed, the reaction mixture was heated to $150{ }^{\circ} \mathrm{C}$ for 3 days. The reaction was then cooled to $50{ }^{\circ} \mathrm{C}$. At this temperature, petroleum ether $(15 \mathrm{~mL})$ was added. After $10 \mathrm{~min}$ of stirring, the precipitate was filtered off. The yellow liquid recovered was placed under vacuum to give the desired compound $3.30 \mathrm{~g}\left(51 \%\right.$ yield). ${ }^{1} \mathrm{H}$ NMR $\left(500 \mathrm{MHz}, \mathrm{CDCl}_{3}, 298 \mathrm{~K}\right): \delta 0.67(\mathrm{~m}, 4 \mathrm{H}$, $\left.\mathrm{CH}_{2} \mathrm{CH}_{2} \mathrm{Si}\right), 1.76\left(\mathrm{~m}, 4 \mathrm{H}, \mathrm{CH}_{2} \mathrm{CH}_{2} \mathrm{Si}\right), 2.50\left(\mathrm{~m}, 4 \mathrm{H},=\mathrm{CHCH}_{2} \mathrm{CH}_{2} \mathrm{CO}\right), 3.59\left(\mathrm{~s}, 18 \mathrm{H}, \mathrm{SiOCH}_{3}\right)$, $4.07\left(\mathrm{~m}, 4 \mathrm{H}, \mathrm{CH}_{2} \mathrm{CH}_{2} \mathrm{OCO}\right), 5.85(\mathrm{~d}, J=16 \mathrm{~Hz}, 1 \mathrm{H}, \mathrm{OCOCH}=\mathrm{CH}), 6.93(\mathrm{~m}, 1 \mathrm{H}$, $\mathrm{OCOCH}=\mathrm{CH})\left(\right.$ Figure S5). ${ }^{13} \mathrm{C}\left\{{ }^{1} \mathrm{H}\right\} \mathrm{NMR}\left(125 \mathrm{MHz}, \mathrm{CDCl}_{3}, 298 \mathrm{~K}\right): \delta 5.2\left(\mathrm{CH}_{2} \mathrm{CH}_{2} \mathrm{Si}\right)$, $21.9\left(\mathrm{CH}_{2} \mathrm{CH}_{2} \mathrm{Si}\right), 27.1\left(=\mathrm{CHCH}_{2} \mathrm{CH}_{2} \mathrm{CO}\right), 32.3\left(=\mathrm{CHCH}_{2} \mathrm{CH}_{2} \mathrm{CO}\right), 50.1\left(\mathrm{SiOCH}_{3}\right), 66.3$ $\left(\mathrm{CH}_{2} \mathrm{CH}_{2} \mathrm{OCO}\right), 121.9(\mathrm{OCOCH}=\mathrm{CH}), 146.5(\mathrm{OCOCH}=\mathrm{CH}), 166.0(\mathrm{OCOCH}=\mathrm{CH}), 171.9$ $\left(\mathrm{CH}_{2} \mathrm{COOCH}_{2}\right)$ (Figure S6). ESI-HRMS: $[\mathrm{M}+\mathrm{Na}]^{+}\left(\mathrm{C}_{18} \mathrm{H}_{36} \mathrm{O}_{10} \mathrm{NaSi}_{2}\right)$ calcd (g.mol $\left.{ }^{-1}\right)$ : 
491.1745, found: 491.1739 (Figure S7). FTIR $\left(\mathrm{cm}^{-1}\right): v 2943(\mathrm{C}-\mathrm{H}) ; 2841(\mathrm{C}-\mathrm{H}) ; 1720.50$ $(\mathrm{C}=\mathrm{O}) ; 1263(\mathrm{C}-\mathrm{O}) ; 1188(\mathrm{Si}-\mathrm{O}-\mathrm{C}) ; 1074(\mathrm{C}-\mathrm{H}) ; 776(\mathrm{Si}-\mathrm{O}-\mathrm{C})$ (Figure S8).

Synthesis of CTA 5. Under argon atmosphere, a $50 \mathrm{~mL}$ round-bottom Schlenk flask equipped with a magnetic stir bar, was charged sequentially with 2-butene-1,4-diol (2.1 g, 2.0 $\mathrm{mL}, 24.3 \mathrm{mmol}$ ) and 3-(trimethoxysilyl)propyl isocyanate $(10.3 \mathrm{~g}, 9.6 \mathrm{~mL}, 50.0 \mathrm{mmol})$. The reaction mixture was placed at $80^{\circ} \mathrm{C}$ for 3 days. The desired product was obtained as a yellow oil (11.8 g, 98\% yield). ${ }^{1} \mathrm{H}$ NMR (500 MHz, $\left.\mathrm{CDCl}_{3}, 298 \mathrm{~K}\right): \delta 0.47(\mathrm{~d}, J=8.6 \mathrm{~Hz}, 4 \mathrm{H}$, $\mathrm{CH}_{2} \mathrm{CH}_{2} \mathrm{Si}$ ), 1.44 (m, 4H, $\mathrm{CH}_{2} \mathrm{CH}_{2} \mathrm{Si}$ ), 2.98 (m, 4H, $\mathrm{CH}_{2} \mathrm{CH}_{2} \mathrm{NHCO}$ ), 3.39 (s, $18 \mathrm{H}, \mathrm{SiOCH}_{3}$ ), $4.47\left(\mathrm{~s}, 4 \mathrm{H}, \mathrm{CH}=\mathrm{CHCH}_{2} \mathrm{O}\right), 5.53(\mathrm{~m}, 2 \mathrm{H}, \mathrm{CH}=\mathrm{CH})$ (Figure S9). ${ }^{13} \mathrm{C}\left\{{ }^{1} \mathrm{H}\right\} \mathrm{NMR}(125 \mathrm{MHz}$, $\left.\mathrm{CDCl}_{3}, 298 \mathrm{~K}\right): \delta 6.1\left(\mathrm{CH}_{2} \mathrm{CH}_{2} \mathrm{Si}\right), 22.9\left(\mathrm{CH}_{2} \mathrm{CH}_{2} \mathrm{Si}\right), 43.2\left(\mathrm{CH}_{2} \mathrm{CH}_{2} \mathrm{NHCO}\right), 50.3\left(\mathrm{SiOCH}_{3}\right)$, $60.0\left(\mathrm{CH}=\mathrm{CHCH}_{2} \mathrm{O}\right), 128.1(\mathrm{CH}=\mathrm{CH}), 156.2(\mathrm{OCONH})\left(\right.$ Figure S10). ESI-HRMS: $[\mathrm{M}+\mathrm{Na}]^{+}$ $\left(\mathrm{C}_{18} \mathrm{H}_{32} \mathrm{~N}_{2} \mathrm{O}_{10} \mathrm{NaSi}_{2}\right)$ calcd (g.mol $\left.{ }^{-1}\right): 521.1963$, found: 521.1968 (Figure S11). FTIR (cm $\left.{ }^{-1}\right)$ : v $3337(\mathrm{~N}-\mathrm{H}) ; 2941.44(\mathrm{C}-\mathrm{H}) ; 2841(\mathrm{C}-\mathrm{H}) ; 1697.36(\mathrm{C}=\mathrm{O}) ; 1526(\mathrm{C}-\mathrm{N}) ; 1238(\mathrm{C}-\mathrm{O}) ; 1072$ (Si-O-C); $988(\mathrm{C}-\mathrm{H}) ; 773$ (Si-O-C) (Figure S12).

Synthesis of CTA 6. Under argon atmosphere, a $50 \mathrm{~mL}$ round-bottom Schlenk flask, equipped with a magnetic stir bar, was charged sequentially with $N, N^{\prime}$-diethyl-2-butene-1,4diamine $(421 \mathrm{mg}, 0.5 \mathrm{~mL}, 3.0 \mathrm{mmol})$ and 3-(trimethoxysilyl)propyl isocyanate $(1.21 \mathrm{~g}, 1.1$ $\mathrm{mL}, 6.0 \mathrm{mmol}$ ). The reaction mixture was placed at $80{ }^{\circ} \mathrm{C}$ for 3 days. The desired product was obtained as a yellow oil (1.60 g, 99\% yield). ${ }^{1} \mathrm{H}$ NMR (500 MHz, $\left.\mathrm{CDCl}_{3}, 298 \mathrm{~K}\right): \delta 0.59$ (t, $\left.J=8.4 \mathrm{~Hz}, 4 \mathrm{H}, \mathrm{CH}_{2} \mathrm{CH}_{2} \mathrm{Si}\right), 1.05\left(\mathrm{t}, J=7.1 \mathrm{~Hz}, 6 \mathrm{H}, \mathrm{NCH}_{2} \mathrm{CH}_{3}\right), 1.54\left(\mathrm{~m}, 4 \mathrm{H}, \mathrm{CH}_{2} \mathrm{CH}_{2} \mathrm{Si}\right)$, $3.16\left(\mathrm{~m}, 4 \mathrm{H}, \mathrm{CH}_{2} \mathrm{CH}_{2} \mathrm{NHCO}, 4 \mathrm{H}, \mathrm{NCH}_{2} \mathrm{CH}_{3}\right), 3.50\left(\mathrm{~s}, 18 \mathrm{H}, \mathrm{SiOCH}_{3}\right), 3.77(\mathrm{~s}, 4 \mathrm{H}$, $\left.\mathrm{CH}=\mathrm{CHCH}_{2}\right), 4.56(\mathrm{t}, \mathrm{J}=5.8 \mathrm{~Hz}, 2 \mathrm{H}, \mathrm{NH}), 5.52(\mathrm{~s}, 2 \mathrm{H}, \mathrm{CH}=\mathrm{CH})\left(\right.$ Figure S13). ${ }^{13} \mathrm{C}\left\{{ }^{1} \mathrm{H}\right\}$ NMR (125 MHz, $\left.\mathrm{CDCl}_{3}, 298 \mathrm{~K}\right): \delta 1.8\left(\mathrm{NCH}_{2} \mathrm{CH}_{3}\right), 6.4\left(\mathrm{CH}_{2} \mathrm{CH}_{2} \mathrm{Si}\right), 13.5\left(\mathrm{CH}_{2} \mathrm{CH}_{2} \mathrm{Si}\right), 41.3$ $\left(\mathrm{CH}_{2} \mathrm{CH}_{2} \mathrm{NHCO}\right), 43.1\left(\mathrm{NCH}_{2} \mathrm{CH}_{3}\right), 47.8\left(\mathrm{CH}=\mathrm{CHCH}_{2} \mathrm{~N}\right), 50.5\left(\mathrm{SiOCH}_{3}\right), 128.5(\mathrm{CH}=\mathrm{CH})$, 157.5 (CO) (Figure S14). ESI-HRMS: $[\mathrm{M}+\mathrm{Na}]^{+}\left(\mathrm{C}_{18} \mathrm{H}_{32} \mathrm{~N}_{2} \mathrm{O}_{10} \mathrm{NaSi}_{2}\right)$, calcd (g.mol $\left.{ }^{-1}\right)$ : 575.2908, found: 575.2908 (Figure S15). FTIR $\left(\mathrm{cm}^{-1}\right): v 3346(\mathrm{~N}-\mathrm{H}) ; 2939.52(\mathrm{C}-\mathrm{H}) ; 2839$ 
$(\mathrm{C}-\mathrm{H}) ; 1624(\mathrm{C}=\mathrm{O}) ; 1526(\mathrm{C}-\mathrm{N}) ; 1279(\mathrm{C}-\mathrm{O}) ; 1074(\mathrm{Si}-\mathrm{O}-\mathrm{C}) ; 972(\mathrm{C}-\mathrm{H}) ; 766$ (Si-O-C)

(Figure S16).

General ROMP Procedure. All polymerizations were performed according to the following typical procedure (Table 1, entry 1 ). The only differences lie in the nature of the solvent, catalyst, CTA and its initial concentration $\left([\mathrm{COE}]_{0}\right.$ and $\left.[\mathrm{CTA}]_{0}\right)$. Under argon atmosphere, a $20 \mathrm{~mL}$ Schlenk flask, equipped with a magnetic stir bar, was charged sequentially with dry $\mathrm{CH}_{2} \mathrm{Cl}_{2}(5.0 \mathrm{~mL}), \mathrm{COE}(1.56 \mathrm{~mL}, 1.32 \mathrm{~g}, 12.0 \mathrm{mmol})$ and CTA 2 (89 $\mathrm{mg}, 0.30 \mathrm{mmol})$. The resulting solution was placed at $40{ }^{\circ} \mathrm{C}$ and the polymerization was started upon addition, via a cannula, of a dry, freshly prepared $\mathrm{CH}_{2} \mathrm{Cl}_{2}$ solution $(2.0 \mathrm{~mL})$ of G2 $(5.0 \mathrm{mg}, 5.3 \mu \mathrm{mol})$. The reaction mixture turned highly viscous within $2 \mathrm{~min}$. The viscosity then slowly decreased over the next $10 \mathrm{~min}$. After the desired reaction time (typically $24 \mathrm{~h}$ ), volatiles were removed under vacuum. The polymer was then recovered upon precipitation in excess methanol $(50 \mathrm{~mL})$, thereby allowing removal of the catalyst residues, filtration and drying at $25{ }^{\circ} \mathrm{C}$ under vacuum $(95 \%$ yield). All polymers were recovered as white powders, readily soluble in chloroform and THF, and insoluble in methanol (Tables 1 and 2).

\section{Separation of cyclic non-functionalized (CNF) polymers from functionalized}

polymers. CNF PCOE was separated from crude polymers by column chromatography on silica gel 60 acidified with $\mathrm{HCl}(37 \%)$ until $\mathrm{pH}<2$, using $\mathrm{CH}_{2} \mathrm{Cl}_{2}$ as eluent. Functionalized polymers (DF) thus remained grafted onto the acidified silica, while CNF PCOEs were isolated from the eluted solution.

\section{Acknowledgements}

Financial support of this research by Bostik and Total Cies (Ph.D. grant to X.M.) is gratefully acknowledged. OmegaCat Company is gratefully acknowledged for providing $\mathbf{M 7}_{3}$-SIMes and $\mathbf{M 7}_{3}$-SIPr catalysts. 
Supporting information includes ${ }^{1} \mathrm{H}$ and ${ }^{13} \mathrm{C}\left\{{ }^{1} \mathrm{H}\right\}$ NMR spectra, FTIR spectra, mass spectra as well as SEC traces of CTAs, and representative PCOE samples. 


\section{References and Notes}

1 T. W. Greenle, Adhesion Science and Technology, A, 1975, 339 (H. L. Lee Plenum, New York).

2 Y. Nomura, A. Sato, S. Sato, H. Mori and T. Endo, J. Polym. Sci. A: Polym. Chem., 2007, 45, 2689-2704.

3 A. Hirao, T. Hatayama, T. Nagawa, M. Yamaguchi, K. Yamaguchi and S. Nakahama, Macromolecules, 1987, 20, 242-247.

4 A. Hirao, T. Nagawa, T. Hatayama, K. Yamaguchi and S. Nakahama, Macromolecules, 1985, 18, 2101-2105.

5 K. Tekenaka, A. Hirao, T. Hattori and S. Nakahama, Macromolecules, 1987, 20, $2035-$ 2037.

6 K. Tekenaka, A. Hirao, T. Hattori and S. Nakahama, Macromolecules, 1989, 22, $1563-$ 1567.

7 K. Tekenaka, K. Kato, A. Hirao, T. Hattori and S. Nakahama, Macromolecules, 1990, 23, 3619-3625.

8 H. Ozaki, A. Hirao and S. Nakahama, Macromolecules, 1992, 25, 1391-1395.

9 M. Kobayashi, T. Chiba, K. Tsuda and M. Takeishi, J. Polym. Sci. A: Polym. Chem., 2005, 43, 2754-2764.

10 A. Hirao and S. Nakahama, Prog. Polym. Sci., 1992, 17, 283-317.

11 W. E. Lindsell, K. Radha and I. Soutar, Polym. Int., 1991, 25, 1-6.

12 A. K. Roy, Dow Corning Corp., US Pat. 5,561,210, 1996.

13 D. Derouet, S. Forgeard and J.-C. Brosse, Macromol. Chem. Phys., 1998, 199, 1835 1842 .

14 D. Derouet, S. Forgeard and J.-C. Brosse, Macromol. Chem. Phys., 1999, 200, 10-24.

15 C.-W. Lee, S.-W. Joo and M.-S. Gong, Sens. Actuat., B, 2005, 105, 150-158.

16 F. Schapman, J. P. Couvercelle and C. Bunel, Polymer, 1998, 39 (20), 4955-4962.

17 K. Takenaka, A. Hirao and S. Nakahama, Makromol. Chem., 1992, 193, 1943-1953.

18 K. Takenaka, S. Kawamoto, M. Miya, H. Takeshita and T. Shiomi, Polym. Int., 2010, 59, 891-895.

19 B. P. S. Chauhan and B. Balagam, Macromolecules, 2006, 39, 2010-2012.

20 H. Nagashima, C. Itonaga, J. Yasuhara, Y. Motoyama and K. Matsubara, Organometallics, 2004, 23, 5779-5786. 
P. Atallah, K. B. Wagener and M. D. Schulz, Macromolecules, 2013, 46, 4735-4741.

A. C. Chruch, J. H. Pawlow and K. B. Wagener, Macromolecules, 2002, 35, 5746-5751.

A. C. Chruch, J. H. Pawlow and K. B. Wagener, Macromol. Chem. Phys., 2003, 204, 32-39.

P. P. Matloka, and K. B. Wagener, J. Polym. Sci. A: Polym. Chem., 2006, 257, 89-98. P. P. Matloka, Z. Kean, M. Greenfild and K. B. Wagener, J. Polym. Sci. A: Polym. Chem., 2008, 46, 3992-4011.

P. P. Matloka, J. C. Sworen, F. Zuluaga and K. B. Wagener, Macromol. Chem. Phys., 2005, 206, 218-226.

E. Malecka, B. Marciniec, C. Pietraszuk, A. C. Church and K. B. Wagener, J. Mol. Catal. A: Chem., 2002, 190, 27-31.

K. B. Wagener and J. C. Marmo, Macromol. Rapid Commun., 1995, 16, 557-561.

A. K. Diallo, X. Michel, S. Fouquay, G. Michaud, F. Simon, J.-M. Brusson, S. M.

Guillaume and J.-F. Carpentier, Macromolecules, 2015, 48, 7453-7465.

C. W. Bielawski, T. Morita and R. H. Grubbs, Macromolecules, 2000, 33, 678-680.

M. K. Mahanthappa, F. S. Bates and M. A. Hillmyer, Macromolecules, 2005, 38, 78907894.

B. R. Maughon, T. Morita, C. W. Bielawski and R. H. Grubbs, Macromolecules, 2000, 33, 1929-1935.

K. Sill and T. Emrick, J. Polym. Sci. A: Polym. Chem., 2005, 43, 5429-5439.

H. Martinez and M. A. Hillmyer, Macromolecules, 2014, 47, 479-485.

C. W. Bielawski, D. Benitez, T. Morita and R. H. Grubbs, Macromolecules, 2001, 34, 8610-8618.

J. B. Matson and R. H. Grubbs, Macromolecules, 2010, 43, 213-221.

N. Hanik and A. F. M. Kilbinger, J. Polym. Sci. A: Polym. Chem., 2013, 51, 4183-4190.

J. B. Matson, S. C. Virgil and R. H. Grubbs, J. Am. Chem. Soc., 2009, 131, 3355-3362.

T. Morita, B. R. Maughon, C. W. Bielawski and R. H. Grubbs, Macromolecules, 2000, 33, 6621-6623.

L. M. Pitet and Hillmyer, M. A. Macromolecules, 2011, 44, 2378-2381.

S. Ji, T. R. Hoye and C. W. Macosko, Macromolecules, 2004, 37, 5485-5489.

S. Ji, T. R. Hoye and C. W. Macosko, Polymer, 2008, 49, 5307-5313. 
44 L. Annunziata, S. Fouquay, G. Michaud, F. Simon, S. M. Guillaume and J.-F. Carpentier, Polym. Chem., 2013, 4, 1313-1316.

L. M. Pitet, M. A. Amendt and M. A. Hillmyer, J. Am. Chem. Soc., 2010, 132, 82308231.

C. W. Bielawski, O. A. Scherman and R. H. Grubbs, Polymer, 2001, 42, 4939-4945.

R. M. Thomas, R. H. Grubbs, Macromolecules, 2010, 43, 3705-3709.

R. J. P. Corriu, J. J. E. Moreau, P. Thepot and M. W. C. Man, Chem. Mater., 1992, 4, 1217-1224.

A. K. Simonian, J. L. Webb, D. J. Brunell, T. E. Banach and S. Rubinsztajn, Eur. Pat. $0900801,27.08 .1997$.

J. Stein, US Pat. 6,296,944, 2001.

The "non-functionalized" PCOE is made of CNF but also of linear polymers which may arise from the direct initiation of ROMP by G2, especially when the CTA is not reacting (entries 1 and 11). Linear products may also be formed in small amounts through the eventual decomposition (during workup) of the Ru-activated linear polymer chain such as II/III (Scheme 1).

R. H. Grubbs and M. A. Hillmyer, Macromolecules, 1995, 28, 8662-8667.

C. Pietraszuk, B. Marciniec, S. Rogalski and H. Fischer, J. Mol. Catal. A Chem., 2005, 240, 67-71.

M. Ulman and R. H. Grubbs, Organometallics, 1988, 17, 2484-2489.

GLC and NMR analyses did not reveal the presence of residual DMAP, which is used in the synthesis of CTAs 3-OMe, 3-OEt or isom-4. Indeed, DMAP is known to inhibit Ru-based metathesis catalysts: purposely added DMAP (1 equiv vs. [Ru]) lowers 5 times the reactivity of the catalyst, while the ROMP reaction was entirely inhibited using 2 or more equiv of DMAP; see: S. J. P'Poo I and H.-J. Schanz, J. Am. Chem. Soc., 2007, 129, 14200-14212.

K. J. Ivin, J. Mol. Catal. A: Chem., 1998, 133, 1-16.

K. Yamamoto, K. Biswas, C. Gaula and S. J. Danishefsky, Tetrahedron Lett., 2003, 44, 3297-3299. 41, 4035-4037. 
60 S. B. Garber, J. S. Kingsbury, B. L. Gray and A. H. Hoveyda, J. Am. Chem. Soc., 2000, 122, 8168-8179.

61 Z.-Y. J. Zhan, US Pat. 0043180, 2007

62 (a) H. Clavier, F. Caijo, E. Borre', D. Rix, F. Boeda, S. P. Nolan and M. Mauduit, Eur. J. Org. Chem., 2009, 25, 4254-4265. (b) D. Rix, F. Caijo, I. Laurent, F. Boeda, H. Clavier, S. P. Nolan, M. Mauduit, J. Org. Chem., 2008, 73, 4225-4228.

63 A. K. Diallo, L. Annunziata, S. Fouquay, G. Michaud, F. Simon, J.-M. Brusson, S. M. Guillaume and J.-F. Carpentier, Polym. Chem., 2014, 5, 2583-2591.

64 C. W. Bielawski, O. A. Scherman and R. H. Grubbs, Polymer, 2001, 42, 4939-4945.

65 L. M. Pitet and M. A. Hillmyer, Macromolecules, 2011, 44, 2378-2381. 


\section{Graphical abstract}

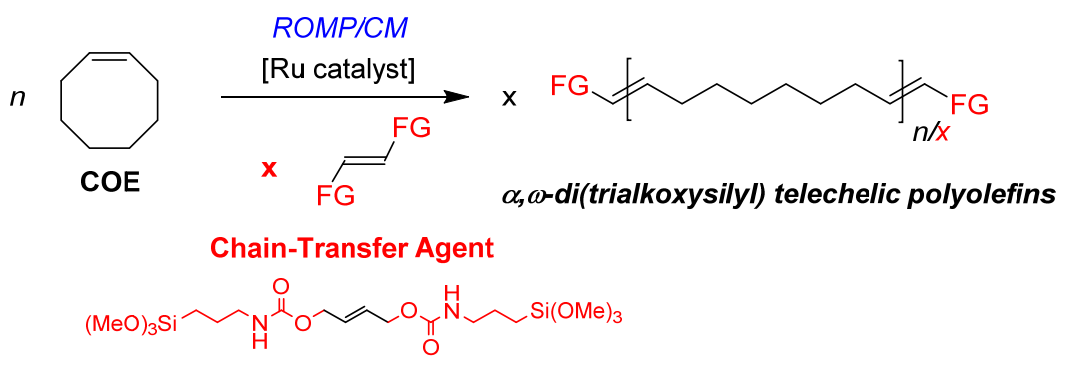

